\title{
1 Advances in understanding ye'elimite-rich cements
}

2 Mohsen Ben Haha ${ }^{a}$, Frank Winnefeld ${ }^{b}$, Alexander Pisch ${ }^{c}$

3 a Global Research and Development, HeidelbergCement AG, Oberklamweg 2-4, 69181 Leimen, Germany

4 b Empa, Swiss Federal Laboratories for Materials Science and Technology, Laboratory for Concrete and

5 Construction Chemistry, Überlandstrasse 129, CH-8600 Dübendorf, Switzerland

6 ' University of Grenoble Alpes, CNRS, Grenoble INP, SIMaP, 38000 Grenoble, France

\section{Abstract}

9 In this review, we discuss the recent advances in understanding ye'elimite-rich cements. These cements

10 can be classified as follows:

11 (1) low belite one namely called calcium sulphoaluminate cements (CSA) where the main use is in special 12 applications or when combined with OPC and calcium sulphate sources in structural application

13 (2) High belite one namely Belite Ye'elimite ferrite cement (BYF) where their development as an 14 alternative low carbon binders is aimed to replace Portland clinker in structural applications. The main hydrating phase at early age in both systems is ye' elimite. Its formation, its reactivity and its extent of reaction and space filling when hydrating define the properties of the cement. Recent advances in understanding these properties are critically analysed.

18 Recent activities on the clinker formation and production at laboratory and industrial scale are reported.

19 Additionally, the effects of aluminates rich minerals are reviewed in detail, with a focus on their influence 20 on the hydration mechanism and the resulting hydrates assemblage and its stability in ye'elimite rich 21 systems. Applicability of thermodynamic calculation and its limitations are discussed to underline the role of the environment at each reaction step on the hydrates assemblage.

This document is the accepted manuscript version of the following article:

Ben Haha, M., Winnefeld, F., \& Pisch, A. (2019). Advances in understanding ye'elimiterich cements. Cement and Concrete Research, 123, 105778 (20 pp.).

https://doi .org/10.1016/j . cemconres. 2019.105778

This manuscript version is made available under the CC-BY-NC-ND 4.0

1icense http://creativecommons.org/1icenses/by-nc-nd/4.0/ 


\section{Introduction}

Sustainability is a key factor for the development of construction industry. In particular, the cement industry in the last decades tried to develop innovative solutions to enhance cement and concrete performances and to reduce the associated $\mathrm{CO}_{2}$ emissions. The development of new binder types is an inherent part of these solutions. In this frame, ye'elimite-rich cements offer potential to lower the environmental impact [1-5].

The production and use of calcium sulphoaluminate-based clinkers (CSA) and cements was initially described by Alexander Klein in the late 1950s, mainly for the shrinkage compensation in PC-based concrete [6]. This lead to the invention of ASTM Type K cement based on the "Klein" compound or ye'elimite which was standardized in ASTM C845-04. A more general use, like in pre-cast concrete or concrete for cold environments was done in China under the name "Third Cement Series" [7].

Research activities focused in the last years either on the ternary CSA-OPC $-C \bar{S}$ systems or on the belite ye'elimite ferrite (BYF) clinkers. In all these studied systems, a particular importance was given to ye'elimite as the main reacting phase at early ages and to the silicate phases that contribute to the microstructure development and the durability of these systems at later ages. However, the activities on clinkering process and especially the associated energies, the saving or the contributions of minors (e.g. Ternesite, $C A$, primary and secondary $C_{12} A_{7}$, etc...) to the overall heat and the data from clinkering at industrial scale are scarce and sometimes failing. Some tentative work on the application of high temperature thermodynamics to BYF clinker formation and semi-industrial testing has been done and could partially compensate this lack of information.

Often pure ye'elimite is used as a model system to study the kinetics of dissolution of these cements. In the actual literature review, the advantages and limitations of this model system are discussed. The kinetics of dissolution and of reaction are described with all reported observed periods or stages of early hydration. The ye'elimite systems are known to be fast when calcium sulphate is added, whereas stoichiometric ye'elimite alone is a slowly reacting. The basic theory of its reaction is discussed where the rate limiting steps are reported. $A$ focus is as well given to the role of $\mathrm{C}_{12} \mathrm{~A}_{7}$ on the kinetics of dissolution as recent studies have shown its importance to describe the chaotic and fast reaction of some CSA. In ye'elimite systems, the aluminate containing phases are the first reacting phases and thus the interaction between the silicate and aluminate hydrates through the pore solution is important to understand. This interaction and the reactivity of silicates is the factor defining the performance of BYF or 
ternary CSA-PC-C $\overline{\mathrm{S}}$ systems. The role of sulphate sources and their impact as well as of retarders on the kinetics of the reaction and partially on the microstructural development is reported.

Thermodynamics and its applicability at early age hydration to define the stable hydrates assemblage are discussed shortly. Its limitations are described. To identify future research needs and to guide our future research and experimental needs, a summary of recent advances with a focus on future perspectives is included.

\section{Clinker formation}

\subsection{Fundamentals of BYF clinkers}

Ye'elimite rich clinkers can be classified in two groups, low belite clinker commonly called CSA and high belite clinker named BYF. The BYF clinkers can be classified in two main groups - with and without boron. In both cases, the main mineralogical clinker phases are belite $C_{2} S$, ye'elimite $C_{4} A_{3} \bar{S}$ and ferrite $C_{4} A F$. The main difference lies in the structural modification of $\mathrm{C}_{2} \mathrm{~S}$ and the presence of an amorphous phase. Without boron addition, $\mathrm{C}_{2} \mathrm{~S}$ crystallizes in the $\beta$-modification (larnite) as in a classical OPC clinker. In the presence of boron, the high temperature modifications $\alpha^{\prime}$ and $\alpha$ can be stabilized even at low temperature [8]. The insertion mechanism of boron in the structure depends on the presence of alkali atoms in the clinker as investigated by Cuesta et al [9]. For a pure sample without alkalis, boron can replace calcium and silicon to form a $\mathrm{Ca}_{2-\mathrm{x}} \mathrm{B}_{\mathrm{x}}\left(\mathrm{SiO}_{4}\right)_{1-\mathrm{x}}\left(\mathrm{BO}_{4}\right)_{\times}$solid solution. The insertion mechanism is similar to the one observed for aluminium in Ca-silicates. In the presence of sodium, the tetrahedral borate anion $\mathrm{BO}_{4}{ }^{5-}$ transforms into a triangular-planar $\mathrm{BO}_{3}{ }^{3-}$ anion with a nominal overall composition of $\mathrm{Ca}_{2-x} \mathrm{Na}_{x}\left(\mathrm{SiO}_{4}\right)_{1-}$ ${ }_{x}\left(\mathrm{BO}_{3}\right)_{x}$ for the solid solution. This new structure proposition gives better fits in Rietveld analyses in clinkers prepared with borax additions.

The presence of an amorphous phase in the clinker is also linked to the presence of boron. Boron oxide is known to be a strong glass forming agent $[10,11]$. Its presence stabilizes the liquid phase and increases its viscosity. Levels of up to $16.5 \%$ of amorphous materials were measured in BYF clinkers using two different experimental methods based on X-ray diffraction [12].

Ye'elimite exists in two stable modifications, a low temperature orthorhombic and a high temperature pseudo-cubic [13]. In BYF clinkers, typically a mixture of both modifications is observed due to the stabilization of the high temperature modification by substitution of minor elements [14]. The highest substitution level is observed with $\mathrm{Fe}^{3+}$ replacing $\mathrm{Al}^{3+}$ in the structure with a maximum up to $25 \%$ (a good review of the available literature is given in [15]). The insertion level of Fe in a BYF clinker depends on the melt relations and the presence of the liquid phase [15]. 
The ferrite phase $\mathrm{Ca}_{2}\left(\mathrm{Fe}_{1-\mathrm{x}}, \mathrm{Al}_{\mathrm{x}}\right)_{2} \mathrm{O}_{5}\left(" \mathrm{C}_{4} \mathrm{AF}\right.$ ") is known to have a large composition range variation with respect to $\mathrm{Al}$ and Fe levels [16]. In the case of BYF clinkers, the composition is generally iron rich with $x=0.2-0.4$. The Fe content is therefore considerably higher than in OPC clinkers in which $x$ varies from 0.5 to 0.6 . The ferrite phase generally forms from an iron rich liquid phase during the cooling step [12]. During the clinkering process, a series of minor phases may appear in a transitory manner. These are generally Al-rich compounds such as mayenite $C_{12} A_{7}$, krotite $C A$ and gehlenite $C_{2} A S$ (or more generally, the melilite solid solution) especially in the presence of traces of chlorine in the raw mix or the combustion gas. This is due to the fact that ye'elimite is thermodynamically unstable at low temperature with respect to $3 \mathrm{CA}+\mathrm{C} \overline{\mathrm{S}}$ (i.e. its Gibbs free energy is greater than zero). Another transitory phase, ternesite $\mathrm{C}_{5} \mathrm{~S}_{2} \overline{\mathrm{S}}$, has gained interest in recent years due to its hydraulic reactivity when present in BYF based cements [15]. This compound can form at temperatures $>900^{\circ} \mathrm{C}$ from $2 \mathrm{C}_{2} \mathrm{~S}+\mathrm{C} \overline{\mathrm{S}}$, but becomes unstable at higher temperature where it decomposes into $\mathrm{C}_{2} \mathrm{~S}$ and liquid. In order to stabilize its presence, a two-step cooling process is proposed [15] during which ternesite forms on cooling by reaction with the melt.

Free lime levels are generally very low in BYF clinkers. In the presence of alkalis, classical soluble alkali sulphate compounds may occur, such as arcanite, aphthitalite or calcium langbeinite. Other potential compounds observed are perovskite $\mathrm{CaTiO}_{3}$ and $\mathrm{Ca}_{3} \mathrm{Fe}_{2} \mathrm{TiO}_{8}$ in high $\mathrm{TiO}_{2}$ bearing raw mixes and periclase $\mathrm{MgO}$ if magnesium is present in excess to the binding capacity of the clinker mineral phases. Substantial amounts of $\mathrm{Mg}$ can be incorporated into the calcium silicates. Bredigte is then the main calcium silicatebearing phase. However, at industrial production, the amount of bredigte is limited. The phase is listed among the minors.

\subsection{Raw mix and alternative raw materials}

As discussed before, BYF clinkers are generally characterized by high levels of alumina and sulphate. While in lab studies pure raw materials such as corundum and quartz can be used, this would be impossible for an industrial application. Suited alternative raw materials for these two components are therefore of great importance. For alumina, high quality china clay (kaolin) and bauxite are a natural choice. However, due to their high price, alternative materials are actively searched. In the literature, low calcium fly ashes (class $F$, class $C)$, ceramic dust waste and aluminium anodizing sludge were tested as alumina sources $[15,17,18]$. For the sulphate, bag house dust, fluidized bed combustion ash, scrubber sludge, flue gas desulphurization gypsum or flue gas sludge, lignite fly ash and phospho-gypsum were used [19-23]. In addition, marble dust and calcium looping spent sorbent were employed as alternative sources for limestone [24,25]. Overall, samples prepared with these alternative raw materials gave satisfactory results in terms of mineralogical composition of the obtained clinkers. 
119 There is only one experimental study which investigates the chemical reactions in BYF clinkers as a

120 function of temperature in a detailed manner [26]. Starting material was an artificial raw mix from pure 121 materials which was placed in a platinum capillary. The mineralogical composition with increasing temperature is studied using synchrotron X-ray powder diffraction (SXRPD) in transmission mode. The diffraction pattern of the platinum is used for temperature calibration. The phase distribution of three BYF clinkers (without, with $1 \%$ and $2 \%$ boron) is reproduced in Fig. 1.

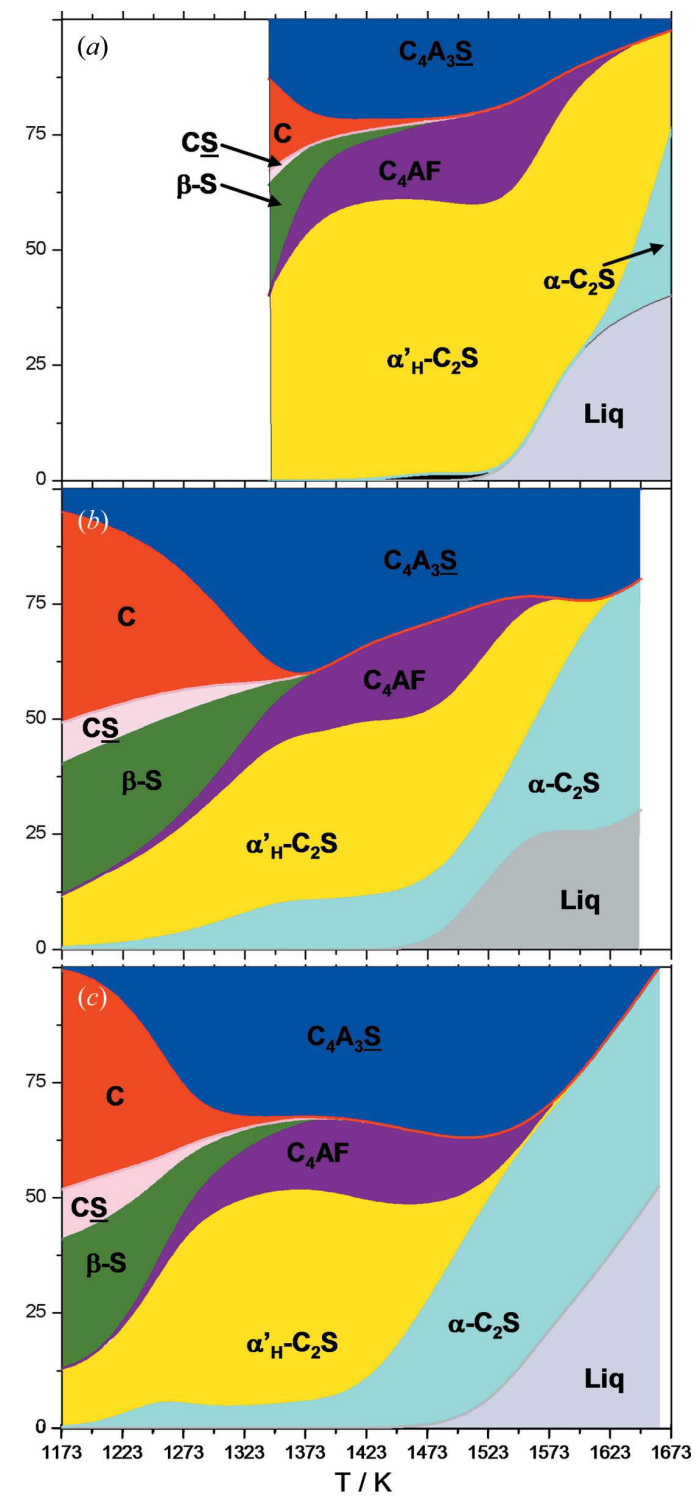


Fig. 1 Phase composition during reaction in a BYF clinker (\%wt) as a function of temperature based on Synchrotron $X$-ray powder diffraction experiments [26] (a) without, (b) with $1 \%$ boron and (c) with $2 \%$ boron addition (copyright needed).

A liquid phase occurs at temperatures as low as $1200^{\circ} \mathrm{C}$ in the boron bearing sample by melting the ferrite phase and to a minor extend by decomposing ye'elimite. It is important to mention, that this phase distribution depends on the process conditions and the volatilization of sulphate from the clinker and is therefore not independent of the experimental set-up. The importance of controlling the $\mathrm{SO}_{2}(\mathrm{~g}) / \mathrm{SO}_{3}(\mathrm{~g})$ partial pressures in the gas phase over the clinker was pointed out by Hanein et al [27]. If the pressure becomes lower than the equilibrium pressure at a given temperature, ye'elimite decomposes and transforms into liquid and $\mathrm{SO}_{2}(\mathrm{~g}) / \mathrm{SO}_{3}(\mathrm{~g})$. The authors derived from their calculations an interesting new process route by using elemental sulphur mixed to the fuel as sulphate source for the clinker [28].

There is no systematic study on clinker microstructures available in the literature for BYF clinkers. However, it is consistently mentioned $[29,30]$ that these clinkers show higher porosity and small crystal sizes as compared to OPC clinkers and therefore improved grindability.

\subsection{Theoretical heat of formation and $\mathrm{CO}_{2}$ balance for BYF clinkers}

142 The theoretical heat of formation for BYF clinkers can be calculated from available thermodynamic data 143 in commercial databases [31] for $\beta-\mathrm{C}_{2} \mathrm{~S}$ and the $\mathrm{Ca}_{2}(\mathrm{Al}, \mathrm{Fe})_{2} \mathrm{O}_{5}$ solid solution and recently published data

144 [32] for $\mathrm{C}_{4} \mathrm{~A}_{3} \overline{\mathrm{S}}$. The starting materials for the calculation are pure limestone $\mathrm{CaCO}_{3}$, kaolinite $145 \mathrm{Al}_{2} \mathrm{Si}_{2} \mathrm{O}_{5}(\mathrm{OH})_{4}$, alumina $\mathrm{Al}_{2} \mathrm{O}_{3}$, hematite $\mathrm{Fe}_{2} \mathrm{O}_{3}$ and anhydrite $\mathrm{CaSO}_{4} . \mathrm{C}_{2} \mathrm{~S}$ and $\mathrm{C}_{4} \mathrm{~A}_{3} \overline{\mathrm{S}}$ are assumed 146 stoichiometric and for the ferrite solid solution, a composition equivalent to $\mathrm{C}_{6} \mathrm{AF}_{2}$ is assumed. For $\mathrm{OPC}$, 147 the accepted heat of formation value of $1760 \mathrm{~kJ} / \mathrm{kg}$ of clinker with $67 \% \mathrm{C}_{3} \mathrm{~S}$ is assumed for comparison 148 [33]. The calculated theoretical heat of formation for a BYF clinker with $50 \% \mathrm{C}_{2} \mathrm{~S}, 30 \% \mathrm{C}_{4} \mathrm{~A}_{3} \overline{\mathrm{S}}$ and $20 \%$ $149 \mathrm{C}_{6} \mathrm{AF}_{2}$ is $1426 \mathrm{~kJ} / \mathrm{kg}$. This value differs from the report value from Barcelo et al (1280 kJ/kg) [22], because the authors used $C_{4} A F$ for the ferrite phase instead of $C_{6} A_{2}$. A theoretical value of $1426 \mathrm{~kJ} / \mathrm{kg}$ corresponds to a reduction of $\sim 20 \%$ as compared to standard OPC. However, it is obvious that such a reduction level cannot be reached in an industrial kiln due to the various heat losses along the production line (waste gas, cooler loss, kiln walls ...). As seen before, the clinkering temperature for BYF clinker is 100 to $150 \mathrm{~K}$ lower than for standard OPC clinkers. However, as losses do not scale linearly with temperature, it is not straightforward to evaluate how much the overall heat of clinkering (theoretical + losses) would be reduced as compared to OPC but a conservative guess would -10 to $-15 \%$ for a given industrial installation. Nevertheless, there are additional advantages of the lower sintering temperature which are the reduced formation of $\mathrm{NO}_{x}$ in the combustion gas and a reduced wear of the refractory bricks in the sintering zone 
of the rotary kiln. These additional advantages must be taken into account while calculating an overall cost of a BYF production.

As seen for the heat of clinkering, the total $\mathrm{CO}_{2}$ reduction depends on the heat losses and therefore on a given installation. The theoretical savings for the chemical part can be calculated exactly because it only depends on the limestone level in the raw mix. In the case of $\mathrm{OPC}$, the $\mathrm{CO}_{2}$ from the raw materials corresponds to $546 \mathrm{~kg} / \mathrm{t}$ of clinker for $67 \% \mathrm{C}_{3} \mathrm{~S}$, while the limestone level in BYF clinkers reduces the emitted $\mathrm{CO}_{2}$ to $376 \mathrm{~kg} / \mathrm{t}$ for a $50 \% \mathrm{C}_{2} \mathrm{~S}, 30 \% \mathrm{C}_{4} \mathrm{~A}_{3} \overline{\mathrm{S}}, 20 \% \mathrm{C}_{4} \mathrm{AF}$ composition which corresponds to a reduction of $31 \%$ [33].

\subsection{Industrial clinker production}

CSA and BYF clinkers are typically produced from mixtures of natural raw materials like limestone, clay or bauxite and calcium sulphate under oxidizing conditions. As for PC, rotary kilns should be preferably used in Fig. 2.

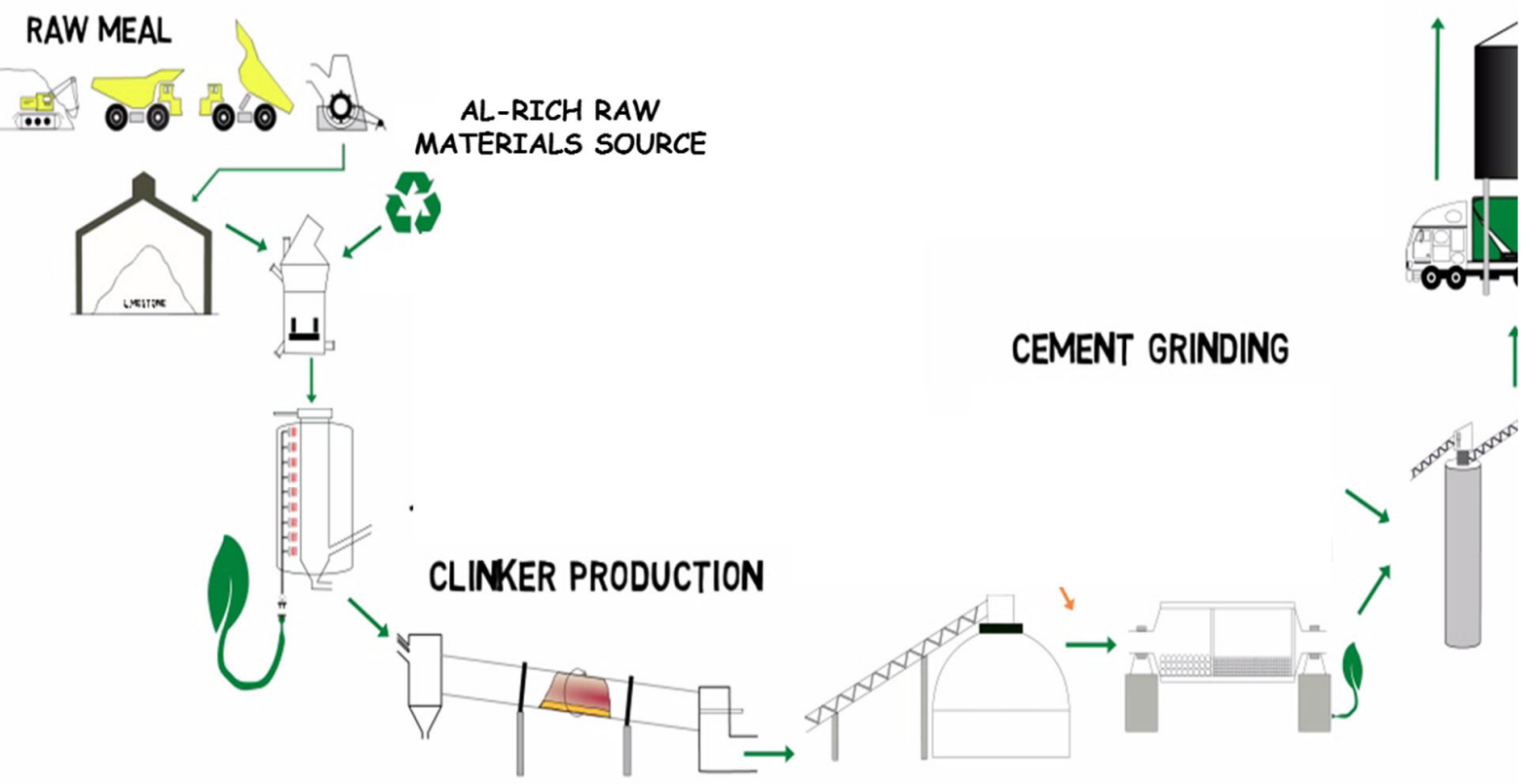
SO3 Source and SiO2 Source, Clinker production at $1250+/-50^{\circ} \mathrm{C}$, Cement grinding: clinker $+/$ - anhydrite or 
Each cement plant has a particular layout and consequently some needs related to quality control have to be adapted to the situation. In addition, BYF clinker production generally requires the implementation of new quality control concepts to properly drive the process.

It is important to stress the importance of a stable raw meal composition and feed to promote formation of the targeted clinker minerals and avoid strong kiln fluctuations impacting quality and operations. As a matter of fact, during BYF industrial production, the high fluctuations in raw meal composition influence the clinker formation at sintering zone temperature and excessive free lime in clinker may occur. The consequence of increased temperature in the kiln is the decrease of the ye'elimite content due to sulphur evaporation, as observed in lab trials and stated before, and the formation of alite [36-38]. The most efficient clinkering temperature is around $1250^{\circ} \mathrm{C}$ and strongly depends on the used raw materials and mix design $[2,39]$. The type of used raw material has a strong impact on the clinker formation and composition as the main minerals like ye'elimite, belite and ferrite can incorporate significant amounts of foreign anions. Mineralizers to reduce the clinkering temperature such as $\mathrm{CaF}_{2}$ might be used. These mineralizers tend to stabilize certain aluminate phases e.g. $C_{12} A_{7}$. Additionally this should also stabilize the formation of F-ellestadite [40]. Another impact arises from the formation of intermediate phases. Depending on the alumina source used, the formation of intermediate phases, e.g gehlenite $\left(C_{2} A S\right)$, CA... occurs and defines the kinetics of the formation in the kiln. As stated before, a novel and very promising approach using elemental sulphur and / or sulphur-rich products as main fuel for the production of CSA / BYF was presented by Hanein et al. [41]. This approach does not only enable the significant reduction of process related $\mathrm{CO}_{2}$ emissions but at least partial replacement of conventional hydrocarbons like oil or coal. The combustion of elemental sulphur will result in the oxidation of sulphur and formation of gaseous $\mathrm{SO}_{2}$. The gaseous $\mathrm{SO}_{2}$ can absorbed from the kiln atmosphere by the reaction with some of the raw materials components. For example, in the system $\mathrm{CaO}-\mathrm{Al}_{2} \mathrm{O}_{3}-\mathrm{SiO}_{2}$ phases like lime, belite and calcium aluminates can react with the gaseous $\mathrm{SO}_{2}$ to form new minerals like anhydrite, ternesite and of course ye'elimite.

As mentioned before, overburning of BYF clinker is not recommended as compared to OPC in case of difficult burnability due to increased sulphur evaporation and decomposition of ye'elimite, so strict control of raw meal production is the most adequate means to guarantee smooth kiln operation and good clinker quality.

The use of X-ray diffractometry in quality control of BYF clinker production is fundamental. Opposite to OPC, where it can be considered a useful complement to conventional XRF analyses, XRD is an essential tool to be implemented in shift labs. The achievement of proper clinker composition by well-adjusted 
burning conditions is only controlled by diffractometry, since chemical analyses cannot prove the correct combination of oxides into the desired amounts of ye'elimite, belite and minors. The clinkering process is sensitive to changes in burning temperatures and the impact those variations have on the final clinker composition.

While operating clinker production, the following point should be controlled:

- $\mathrm{O}_{2}$ in the kiln inlet has to be closely controlled and kept at a minimum level to avoid reducing conditions and $\mathrm{SO}_{\mathrm{x}}$ emissions

- Similar chloride control as OPC clinker production is required to avoid the formation of phases like chloro-mayenite or ellestadite. This means that in certain kiln lines a by-pass would be required

- A pyrometer to monitor burning zone temperature would provide useful information on sintering conditions.

Additional measures shall be placed to reduce ring and ball formation. Better monitoring of the minors content of the raw mix (chlorides) as well as the installation of equipment that would destroy rings/balls from burner platform is needed while producing this clinker type. The kiln shall be operated at much higher rotational speed than usually set for OPC clinker production to reduce the residence time in the sintering zone. BYF clinkers have a tendency to create generally bigger clinker nodules than OPC even if higher kiln speed will be applied. However, at the same time, ye'elimite has a tendency to form small crystals (see Fig. 3 ) in comparison to lab clinkers which may influence its reactivity and have a positive impact on the grindability.

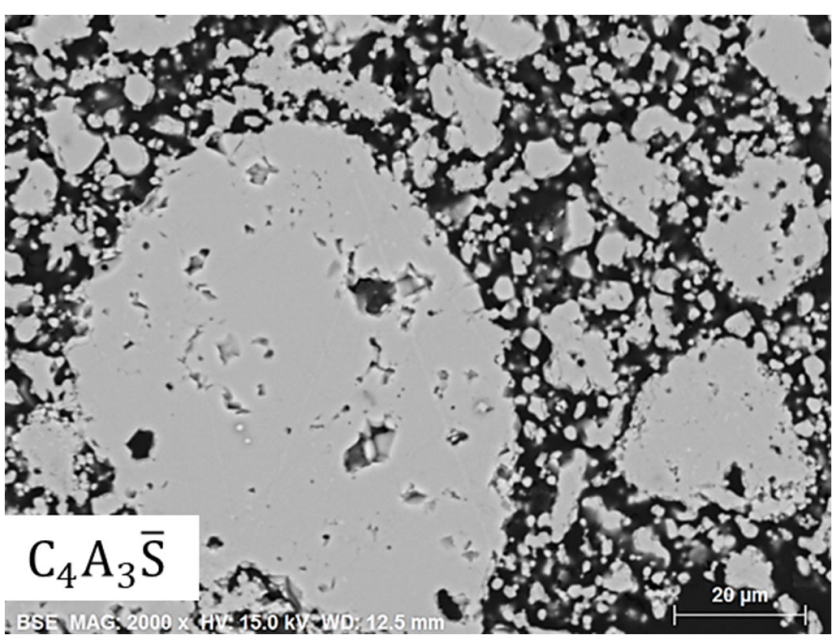



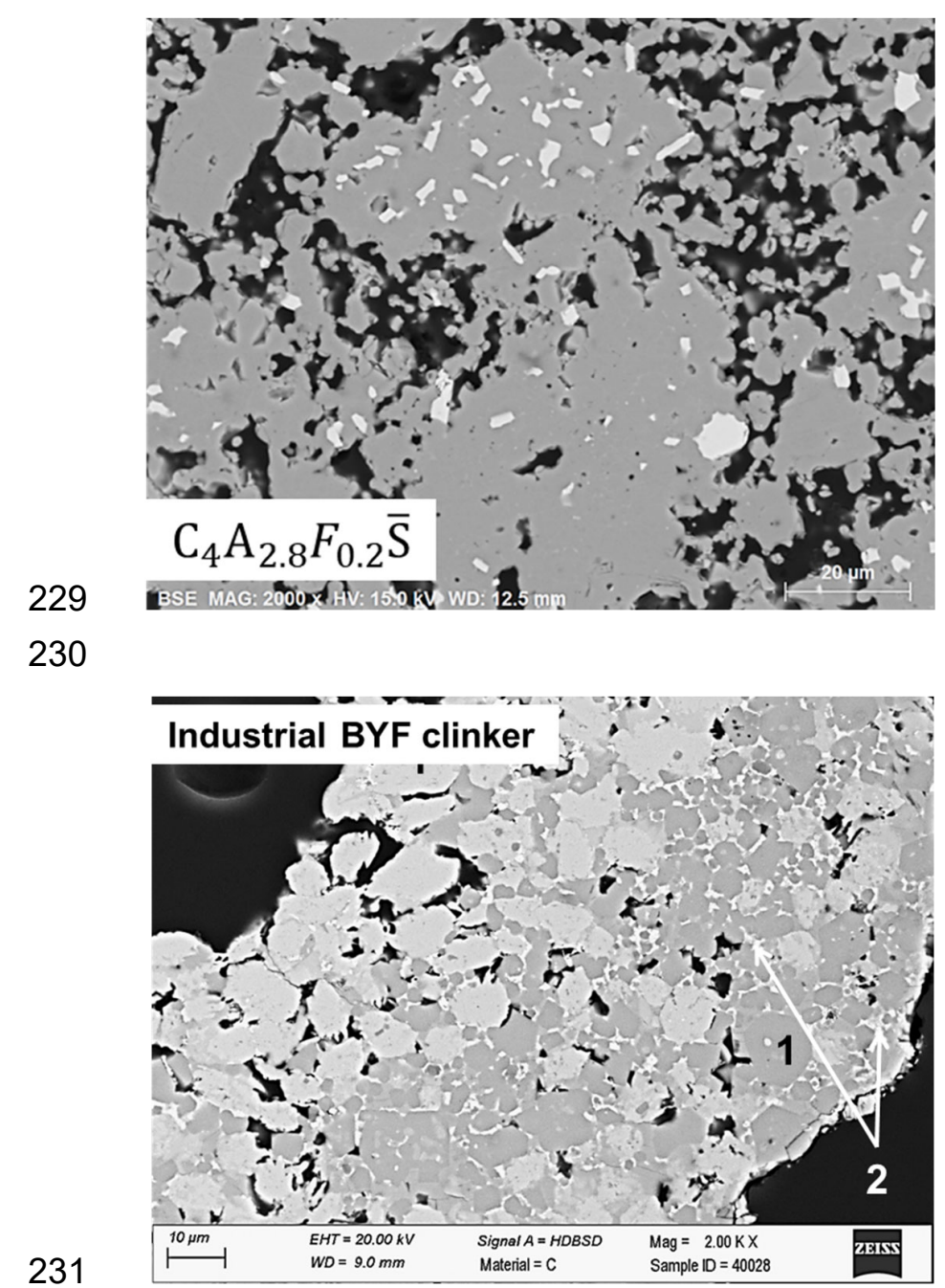

Fig. 3 Scanning electron micrograph of polished sections of $Y$ and Fe-Y and industrial BYF clinker from (1: Ye'elimite, 2:Ferrite) [35]

Other major phases, typically present in CSA and BYF clinkers, are calcium silicates like belite and ternesite as well as calcium ferrites like brownmillerite and srebrodolskite. Many different minor (reactive and inert) phases could be present as well, depending on the raw mix design and the process conditions. When comparing the clinker minerals and their associated $\mathrm{CO}_{2}$ footprint it becomes obvious that the combination of ye'elimite, belite (ternesite) and brownmillerite offers high potential for $\mathrm{CO}_{2}$ saving compared to PC going from from $20 \%$ for high belitic systems BYF to $35 \%$ in the case of CSA [2].

241 Metha [39] proposed Equation 1 for the calculation of the raw mix composition. According to the author 242 it is possible to adjust specific cement features by targeting the appropriate clinker compositions. The 243 cement performance would mainly depend on the ratio of calcium sulphate over ye'elimite [42]. By 
combining Equation 1 with a modified Bogue calculation it would be possible to define the cement 245 properties.

246 Equation $1 \quad C_{T}=\mathbf{0 . 1 3} \cdot \boldsymbol{M} \cdot \frac{A}{\bar{S}}$

247 where $C_{T}$ is the molar ratio of calcium sulphate over clinker; $\mathrm{M}$ is the molar ratio of calcium sulphate over

248 ye'elimite; A is the mass \% of ye'elimite in the clinker and $\bar{S}$ is the mass \% of $\mathrm{SO}_{3}$ in the used calcium

249 sulphate and 0.13 is the stoichiometric factor containing all the conversions between mass and molar 250 units.

2523 Hydration of ye'elimite-based systems

\section{$253 \quad 3.1$ Advantages and limitations of model systems}

254 To simulate the reaction kinetics of the OPC, $C_{3} S$ is often used as a model system. Generally, synthetic $C_{3} S$ 255 have a hydration pattern similar to OPCs regardless of their differences such as fineness or composition 256 allowing its use as model to understand the early kinetics, duration and underlying mechanisms 257 controlling the hydraulic reactions [43-45] (see Fig. 4a).

258 Synthetic ye'elimite is used as a reference system for CSA and BYF by analogy with $C_{3} S$ and OPC. The heat 259 release of different ye'elimite rich cements (CSA, BYF cements, stoichiometric ye'elimite and iron rich 260 ye'elimite cements) normalized to ye'elimite content of the cements are shown in Fig. 4b. CSA, BYF and 261 Fe-ye'elimite cements reveal very different hydration kinetics unlike OPC and $C_{3} S$. In addition, the 262 hydration of synthetic ye'elimite has a different kinetics than that of CSA and BYF and Fe-ye'elimite 263 cements. However, it is possible to use synthetic ye'elimite as a model system to explain the hydration 264 reactions of CSA and BYF if the data are carefully analyzed. 

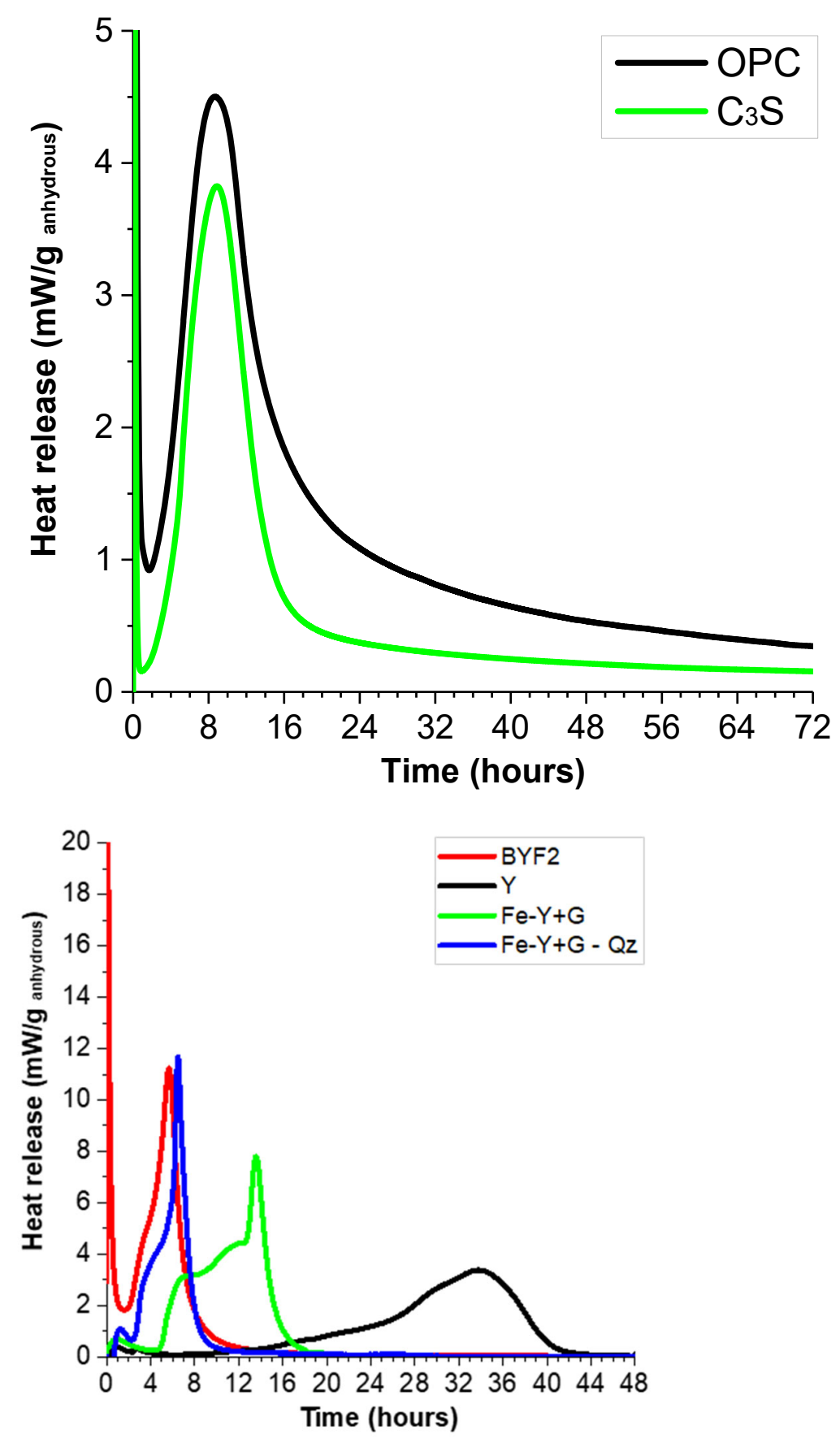

Fig. 4 Rate of heat evolution from isothermal conduction calorimetry of (a) $\mathrm{OPC}$ and $\mathrm{C}_{3} \mathrm{~S}$ at $20^{\circ} \mathrm{C}$ and of (b) CSA, BYF and Fe-Y with and without gypsum at $20^{\circ} \mathrm{C}$. The data are normalized per $\mathrm{g}$ of anhydrous ye'elimite. The water/solid ratios are $\mathbf{0 . 5}$ for the clinker and $\mathbf{2 . 0}$ for the synthetic ye'elimite systems 


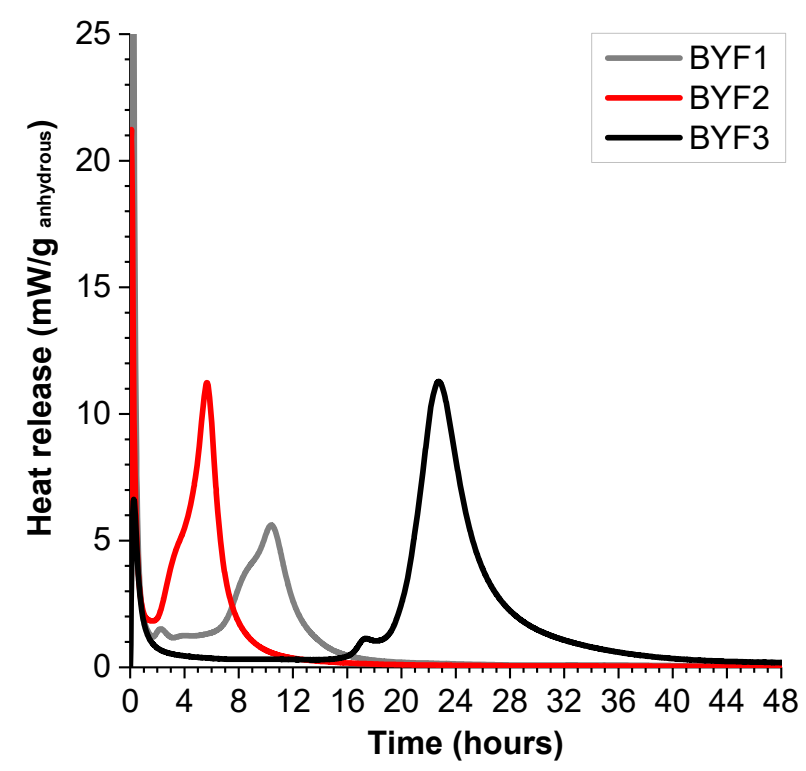

Fig. 5 Rate of heat evolution from isothermal conduction calorimetry of 3 different BYF industrial cements (same mineralogy, only minors and alkalis differs) at $20^{\circ} \mathrm{C}$ at w/c ratio of 0.5

The model system ye'elimite presents a simplified but synthetic picture of the early behaviour of ye'elimite based systems. However, it is necessary to keep in mind that model systems do not represent full reality. It helps to simplify the problem by eliminating other interactions. The investigator can control the increase of the complexity level by adding e.g. alkali sulphates, changing the $\mathrm{pH}$, etc... Using ye'elimite as model system is preferable to study the kinetics when the objectives and limitations of its use are known and precise. Studying a BYF cement, however, is not trivial as the raw materials condition its reactivity and the behaviour differs from one clinker to another (see Fig. 5).

\subsection{Periods of hydration}

In all systems, the calorimetric pattern of hydration clearly shows five different periods (see Fig. 6):

- Initial period "I": Wetting and rapid dissolution of a small quantity of cement

- Induction or slowdown period "II": also referred as low heat activity period

- Acceleration period "III": (Re-) Acceleration of the dissolution of ye'elimite.

- Period of main hydration "IV" including a heat deceleration phase

- Slowing of the reaction " $\mathrm{V}$ ", continuous dissolution of the phases but with transformation, (re)crystallization and growth of hydrates 


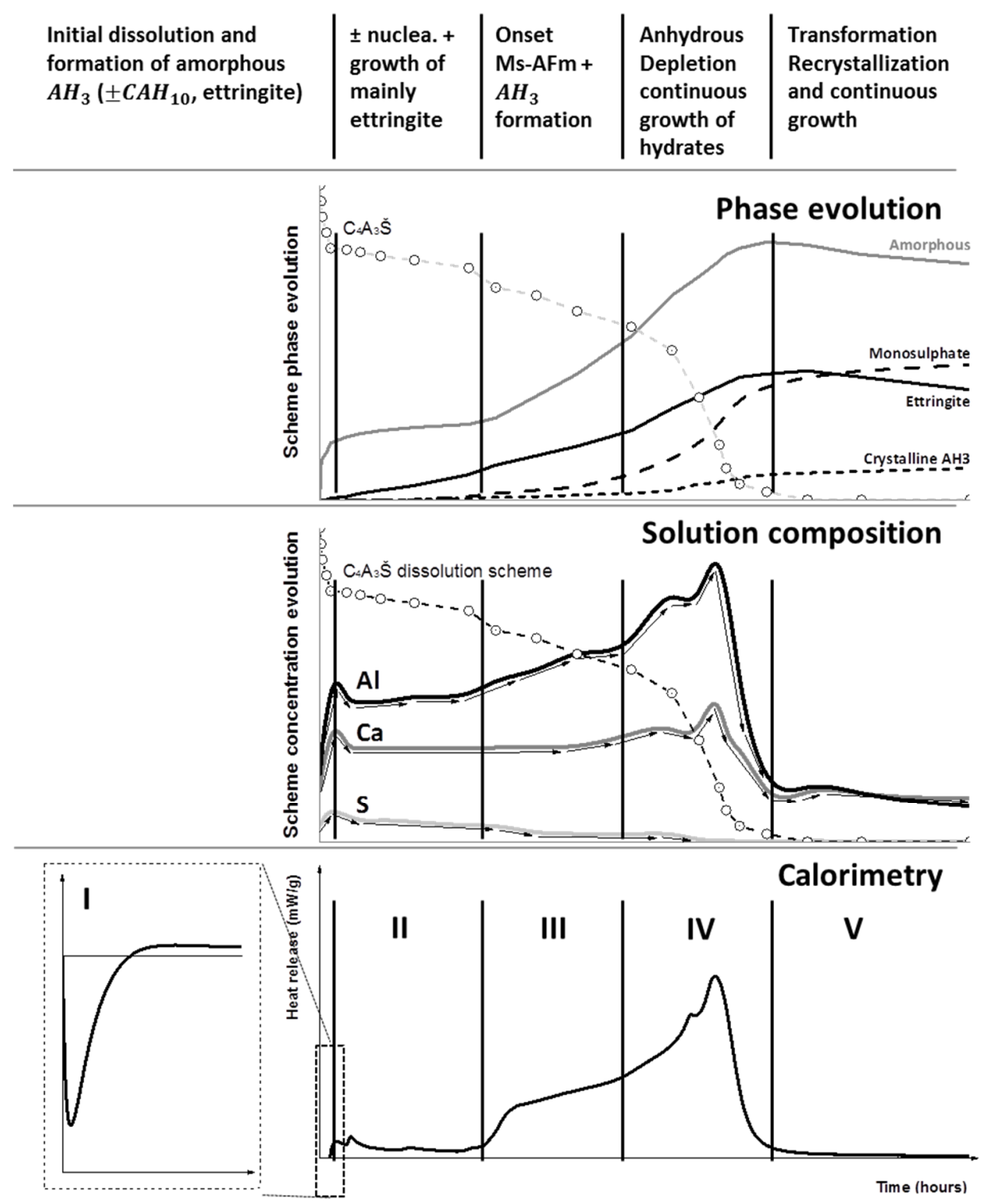

Fig. 6 Idealized hydration scheme for ye'elimite and the corresponding hydration stages from [35] (phase evolution wt\% and concentration ( $\mathrm{mol} / \mathrm{l})$

At the beginning (the initial period), a rapid dissolution in contact with water takes place followed by the formation of mainly amorphous hydrates and some traces of ettringite. The precipitation of amorphous aluminium hydroxide (usually exothermic in the presence of gypsum) has been reported to cause an endothermic reduction in the heat of hydration [35]. The same observation but in alkali activated slag systems were reported by Ben Haha \& al[46] where they observed the presence of an endothermic peak in calorimetry with increasing the alumina content of the slag and keeping the ratios of other oxides constant. A slowing down of the reaction occurs mainly due to a significant increase in the concentration of the different ion species in the solution. 
This increase is followed by an induction period (period II) where almost no dissolution of ye'elimite is detected and where only a continuous formation of the "ettringite" is observed as crystalline detectable hydrate [47]. The formation of ettringite leads to a continuous decrease in the concentration of sulphate ions and controls directly the duration of this period. Following the decrease of the concentrations of the different ionic species in the solution, an acceleration period (period III) where a fast dissolution takes place with the beginning of monosulphate and aluminium hydroxide precipitation. The formation of ettringite slows down progressively and a total exhaustion of the sulphate ions in the solution is observed at the end of this period. The decrease of sulphate is accompanied by a considerable increase of the $\mathrm{pH}$. The main hydration period including the deceleration phase (phase IV) starts once the sulphates species are no longer detected in the solution and the $\mathrm{pH}$ continues to increase. The $\mathrm{pH}$ increase promotes the formation of monosulphate and the crystallisation of gibbsite-type microcrystalline aluminium hydroxide. The duration of this period depends mainly on the dissolution rate of ye'elimite. Once dissolution is slowed down to a negligible extent, a thermodynamic equilibrium between the solution and the hydrates starts to get established. A transformation of amorphous phases and/or (re)crystallization and growth of the different hydrates present leading to a decrease in the concentration of aluminium due to the decreased solubility of the Al-bearing hydrates is observed. Over time the C-A-H gel that precipitates at early hydration time transforms towards (micro)crystalline phases like $\mathrm{CAH}_{10}, \mathrm{C}_{4} \mathrm{AH}_{\mathrm{x}}$ or $\mathrm{C}_{3} \mathrm{AH}_{6}$ together with $\mathrm{AH}_{3}$ whereby the composition of the (final) assemblage depends on the applied temperature and the time

\subsection{Kinetics of dissolution and rate limiting steps}

The pH of BYF cements [48] is higher than for CSA cements with lower belite and ferrite contents [49]. Lower $\mathrm{pH}$ of CSA could be the result of cleaner raw materials used for their production. At comparable alkali content, the early age $\mathrm{pH}$ should be same as it is buffered by type of phases and not by their content. In the literature, several hypotheses are put forward such as the polymorphism of ye'elimite $[50,51]$ or as recently proposed the initial mineralogy composition in addition to crystallinity (morphology) of ye' elimite [52].

Geochemistry can explain the dissolution results as well as the slowdown observed after the increase in solution concentrations [43,53-55]. The dissolution rate is high at the beginning following the addition of water and thus a high degree of under-saturation is observed which promotes the dissolution of ye'elimite from the first minutes as reported by [47,50-52]. Ionic concentrations therefore increase rapidly. The increase in the concentrations of the solution, in particular aluminium and sulphates in relation to calcium ions, slows down the kinetics and limits the dissolution of anhydrous phases. 
The precipitation of monosulphate should happen with the dissolution of ye'elimite to deplete instantly all released sulphate ions. However, some research groups $[47,56,57]$ report a slow decrease in sulphate concentration with the occurrence of a slow formation of ettringite instead. Indeed, ye'elimite dissolution is generally accompanied by high concentrations of aluminium $[35,47,52,58]$. The low $\mathrm{pH}$ limits the precipitation of monosulphate while $\mathrm{AH}_{3}$ precipitation limits the nucleation rate of ettringite as suggested from investigation of Damidot [59] and confirmed by experimental work from Bullerjahn \& al [47]., Additionally thermodynamics calculation from Zajac \& al [60]could confirm from theoretical calculations how the pore solution concentrations and potentially the AH3 precipitation controls further ettringite formation. . Thus, it slows down hydration kinetics creating an induction period.

The potential absorption of sulphate at reactive dissolution sites slows the rate of dissolution as previously observed for $C_{3} A$ studies [61]. An important difference between the hydration of ye'elimite and $C_{3} A$ is that sulphate is part of the crystalline structure of ye'elimite and is released with calcium and aluminium where $\mathrm{C}_{3} \mathrm{~A}$ dissolution releases much less aluminium and more calcium [61] compared to ye'elimite.

The theory of the protective layer or membrane due to an instant precipitation of amorphous phases covering anhydrous grains that constitutes a diffusion barrier that would slow down the dissolution of cement materials as suggested by [62-64] can be eliminated as rate limiting factor of any period. Champenois et al[65] reported that, when the mixing solution contains boric acid (at $1 \mathrm{~mol} / \mathrm{L}$ ), an amorphous borate gel precipitates initially and retards cement hydration by a mechanism which is not fully understood. Several assumptions may be postulated, such as the setting of chemical conditions unfavourable to the dissolution of anhydrous cement phases, or the decrease in the diffusivity of ionic species since this compound precipitates as a very hydrophilic gel-like phase.

However, Few seconds after contact with water and before any layer covers the anhydrous grains, a slowdown of the reaction is already observed $[47,52]$ in a highly stirred solution in suspension experiments. SEM images suggest that no layer is present while the slowing down of the dissolution process is observed [35].

\subsection{Impact of mayenite on the solution composition and hydration kinetics}

Bullerjahn et al [52] studied the hydration of Fe-Y in comparison to stoichiometric ye'elimite. Besides the polymorphism that was investigated previously by other groups [50,51], they found that the main mineralogical difference is the occurrence of the mayenite in the systems with Fe-rich clinker. Secondary mayenite formation is the result of the decomposition of the ye'elimite in Fe-rich clinker [66]. The lower $\mathrm{Al} \mathrm{/} \mathrm{Ca}$ ratio provided by mayenite compared to ye'elimite promotes the nucleation of ettringite. Even if 
higher aluminium concentrations than stoichiometric ye'elimite are present at a given sulphate level, the high calcium concentration coupled to the high aluminium one, promotes a faster and easier nucleation of $C A H_{10}$ and of ettringite $[52,59,67,68]$. This was as well confirmed by the thermodynamic calculation done by Zajac et al. [60]. Since the dissolution and nucleation processes are coupled reactions, any factor favouring one of them will in turn cause the acceleration of both [69].

Bullerjahn et al. [52] could prove that the polymorphism has a limited impact in comparison to the presence of mayenite in the Fe-rich systems. To verify their statement, they added ground synthetic mayenite to stoichiometric ye'elimite. They could reproduce the faster initial reaction as well as the high $\mathrm{pH}$ value observed in Fe-Y during the initial period. A shortening of the induction period was observed as well when comparing both synthetic ye'elimites and the combination of $1 \%$ mayenite and synthetic ye'elimite. In another set of experiments, the role of gypsum on the hydration kinetics of ye'elimite, Feye'elimite and additionally the impact of mayenite additions to stoichiometric ye'elimite was tested in stirred suspensions (see Fig. 8). An identical curve, for both the conductivity and pH evolution between stoichiometric ye'elimite+gypsum (1M/1M) with the addition of mayenite and Fe-ye'elimite+gypsum is observed. The shape of the initial period is reproduced as well. The dissolution of mayenite, even if present in trace amounts, continues during the first few seconds until a few minutes of hydration, modifying the $\mathrm{Al} / \mathrm{Ca}$ and $\mathrm{Al} / \mathrm{S}$ ratios, and thus promoting nucleation and growth of ettringite. As ettringite uses more calcium than is released by the dissolution of ye'elimite, aluminium ion concentration should increase compared to calcium, which is normally the case during the acceleration period. These concentrations of the pore solution favour the precipitation of amorphous aluminium hydroxide and $\mathrm{CAH}_{10}$. The formation and growth of monosulphate may be kinetically hindered. Additionally, literature reports that sulphate ions cause a faster nucleation of amorphous aluminium hydroxide [70-72]. The addition of gypsum leads to a more uniform hydration pattern with an acceleration of the reactions. Based on the findings described by several research groups $[50,51]$ it is evident that the addition of gypsum results in a faster formation of ettringite, almost independently of the ye'elimite composition. The sharp peak at about 13 hours (see Fig. 7) is probably related to the point of the sulphate depletion and reaccelerated ye'elimite dissolution as suggested by Winnefeld and Barlag [73]. 

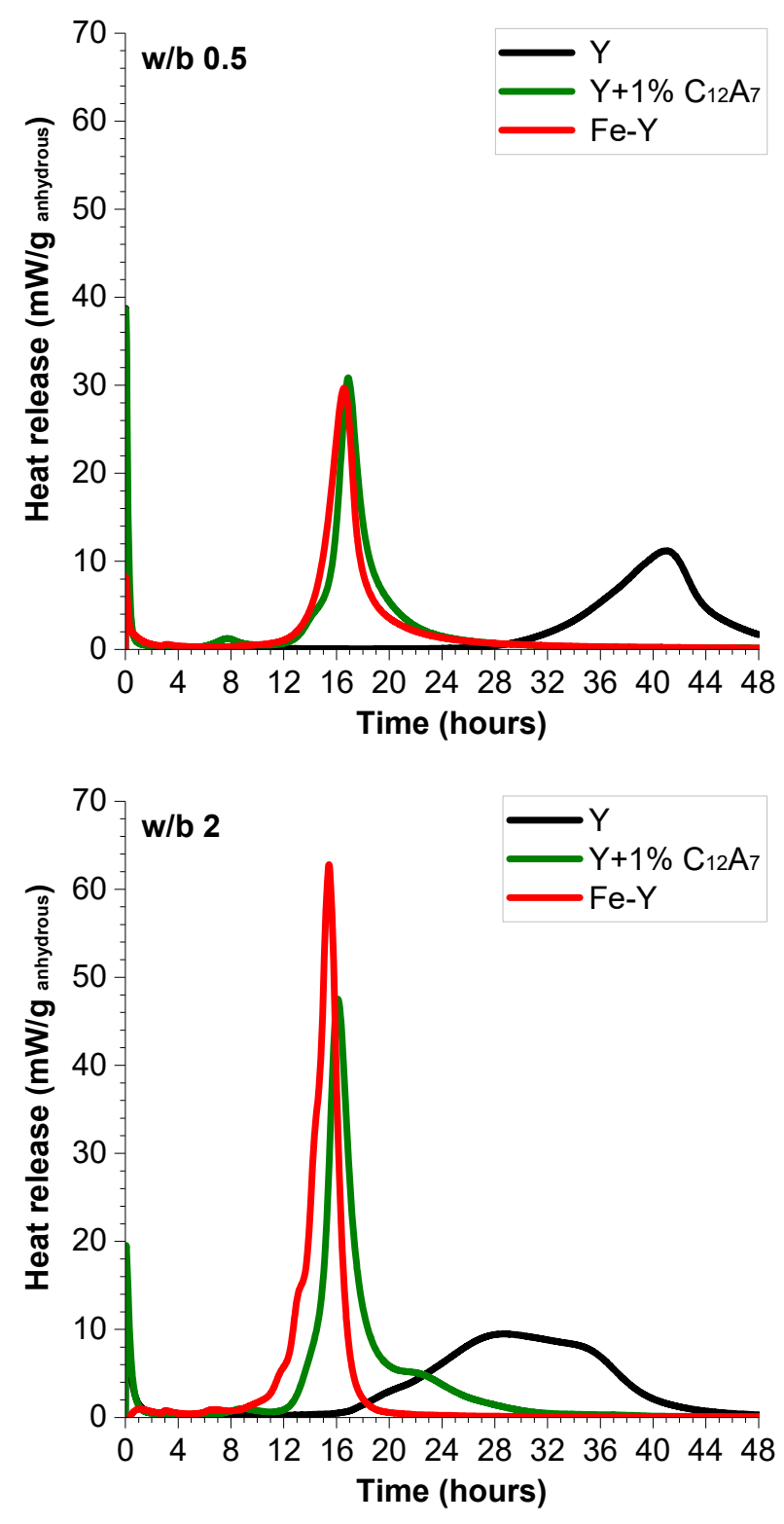

Fig. 7 Comparison of the evolution of the heat hydration of ye'elimite $(Y)$,ye'elimite with 1 wt.\% mayenite $(Y+1 \%$ $\left.\mathrm{C}_{12} \mathrm{~A}_{7}\right)$ and Fe-ye'elimite $(\mathrm{Fe}-\mathrm{Y})$ at $\mathrm{w} / \mathrm{b}=\mathbf{0 . 5}$ and $\mathrm{w} / \mathrm{b}=2$. Adapted from [35]. 


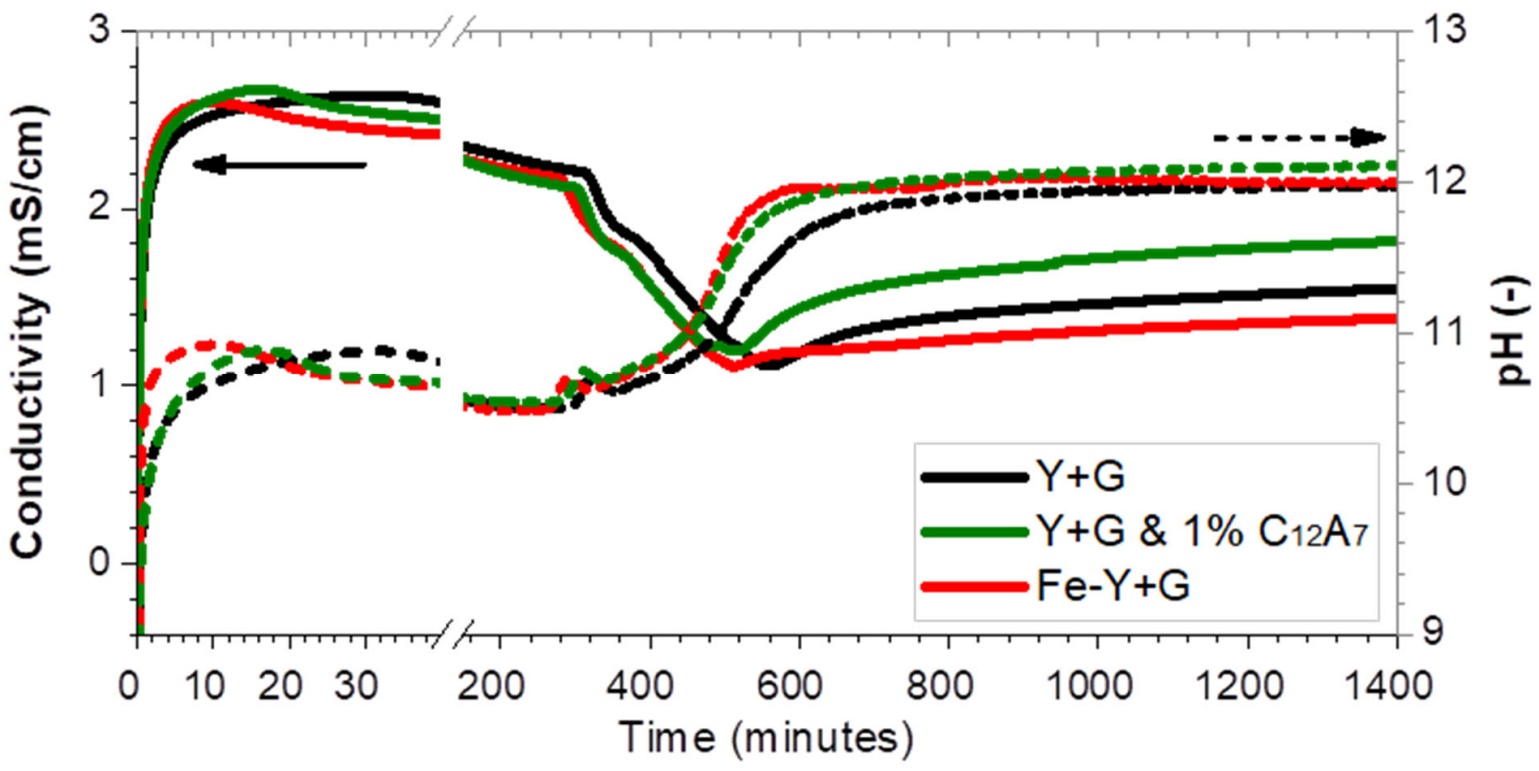

Fig. 8 Evolution of the conductivity and $p H$ of $Y+G$ and $Y+G$ with 1 wt.\% mayenite at $w / b=100, F e-Y+G$ for comparison Y/G 1M/1M. Adapted from [35].

The higher $\mathrm{pH}$ or faster reaction in iron-rich CSA, i.e. Ferro-sulphoaluminate cements (FAC) [74], or synthetic Fe-ye'elimite (Fe-Y: solid solution) [51] can be thus explained by the conditions promoting faster nucleation and growth of ettringite as result of mayenite dissolution and thus faster consumption of sulphates. This depletion of sulphates in the solution is the trigger for the rapid dissolution of ye'elimite and the precipitation of monosulphate. The presence of mayenite as described before results generally from the decomposition of ye'elimite when higher amount of iron is added. Indeed iron additions leads to faster ye'elimite and clinker formation, followed by a faster decomposition of the ye'elimite and sulphur volatilization. Traces of mayenite in ye'elimite-based cements might be as well not easily detectable by XRD.

A similar impact of mayenite on the hydration of calcium aluminates alone and in the presence of gypsum is already known. Raab [75] analyzed the hydration of pure krotite and in the presence of mayenite. He was able to show that the concentration of calcium compared to aluminium ions was higher in the presence of mayenite and that the induction period was shortened. Similarly, the presence of mayenite causes the acceleration of the hydration kinetics of CAC clinker $[64,75]$. 


\subsection{Hydrates at early ages}

$418 \quad 3.5 .1 \quad$ Calcium rich aluminium hydrates

419 The (meta)stability of the hydrates formed is another essential aspect to consider when studying CSA and 420 BYF cements that has been recently highlighted by Winnefeld and Lothenbach [76].

421 The stability of ettringite and AFm phases is often a subject of debate. These phases form solid solutions 422 at the different stages of hydration with different stabilities. The formation kinetics, type of retarder used 423 and the ions present in the pore solution often lead to wide range of solid solutions formed [48,77-80].

424 In cementitious systems, a transformation of ettringite to monosulphate or vice versa is generally observed depending on the alkalinity and sulphate concentration of the pore solution [81]. Recently, the stability of AFm and AFt has been described according to new factors such as relative humidity, water activity and temperature [82-84]. During the different hydration steps, the CSA and BYF pore solution concentrations cover a wide range of $\mathrm{pH}$ and sulphate concentrations. The stability range of ettringite in these systems is still under discussion. Several authors and results reported on the hydration of the different types of cements that ettringite is stable in a pH range of 9 to 13 [45,85-88]. In synthetic systems, and at higher $\mathrm{pH}(>13)$ a morphological change from the needle to the spherical aspect is observed [8991]. At higher $\mathrm{pH}$, the formation and stability of AFm phases are promoted over ettringite [58,92-95]. The (initial) pH of CSA / BYF and ye'elimite which varies from about 10.0 to $11.5[47,48,73,96-100]$ favours the formation of ettringite. Hydration kinetics also influences the formation of metastable phases. For $C_{3} A[61,101]$, its rapid dissolution causes the massive formation of monosulphate in two hydration stages, where "AFm 14H" and "AFm 16H" are favoured to the detriment of ettringite when sulphates are consumed. The AFm $16 \mathrm{H}$ phase is the phase formed at the beginning, but transformed over time into AFm $14 \mathrm{H}$, which is thermodynamically more stable.

440 Amorphous calcium aluminate hydrate (CAH) generally forms during hydration of aluminate and 441 sulphoaluminate cements $[52,57,60,102,103]$ where a chemical composition close to $\mathrm{CAH}_{10}$ is reported 442 [104]. This gel is a metastable phase and dissolves with the progress of hydration to form new metastable 443 intermediate microcrystalline phases such as $\mathrm{C}_{2} \mathrm{AH}_{8}$ or $\mathrm{C}_{3} \mathrm{AH}_{6}$ which is the most thermodynamically stable 444 phase in combination with $\mathrm{AH}_{3}$. Different hydrate assemblages can be formed depending on the initial 445 water, curing conditions, calcium availability, applied temperature and curing time $[105,106]$. Aluminate 446 phases are the phases whose stability is most affected. These phases are the same observed in the early 447 hydration of ye'elimite-based cements $[57,68,76]$. These microscopic changes generally lead to changes 
in macroscopic properties. Indeed phase transformation is generally accompanied by the release of chemically bound water which in turn creates additional porosities and a denser hydrate assemblage is in place [68].

\subsubsection{Aluminium hydroxide}

Recently, the microcrystalline $\mathrm{AH}_{3}$ phase present in CSA has attracted research attention $[50,51,97,107-$ 112]. It forms besides ettringite and monosulphate from ye'elimite in the absence of significant sources of calcium hydroxide $[9,41,42]$ and is generally $X$-ray amorphous. In the microstructure of hardened CSA ettringite-rich and $\mathrm{AH}_{3}$-rich domains can be distinguished, which exhibit different mechanical properties as determined by nanoindentation [116]. Furthermore it is suggested that $\mathrm{AH}_{3}$ might have a positive influence on compressive strength [108].

Phenomena such as transient losses of macroscopic properties and increased porosity [68] are suggested to be related to the formation and crystallization of amorphous aluminium hydroxide.

In geochemistry and especially by studying clays, the formation, composition and stability of (oxyJaluminium hydroxides has been investigated extensively. Aluminium hydroxide is characterized by its high water content in the amorphous state that is released during the recrystallization process. The compositions / concentrations of the solutions and the resulting nucleation rates also influence the type of aluminium hydroxide formed and its crystallinity $[117,118]$. The nature of the initially precipitating aluminum hydroxide changes as a function of the saturation state of the solution[118-120] .The pH below $11[99,109-110]$ favours the formation of amorphous aluminium hydroxide. The increase of temperature and/or curing time increases the crystallinity. Additives, admixtures and retarders to control, delay or inhibit nucleation, influence the morphology and the crystallinity also of this hydrate [109-110]. By mass balance calculations based on QXRD and ${ }^{1} \mathrm{H}$-TD NMR it was found that at early hydration times aluminium hydroxide produced from the reaction of ye'elimite and gypsum contains more water than referring to the formula $\mathrm{AH}_{3}$ (rather $\mathrm{AH}_{\mathrm{x}}$ with $\mathrm{x} \approx 7$ ) [51]. At later ages the water is released again reforming $\mathrm{AH}_{3}$. Bullerjahn et al. [68] reported the release of adsorbed sulphate in addition to the water contribute to the hydration reactions generating additional ettringite. Ptychographic X-ray Computed Tomography was used to study the special distribution of hydrates (Fig. 12), and in particular the properties of the aluminium hydroxide present in ye' elimite-containing pastes [109]. In pure ye'elimite pastes a gel with a high water content containing some calcium with the formula $(\mathrm{CaO})_{0.04} \mathrm{Al}(\mathrm{OH})_{3} \cdot 2.3 \mathrm{H}_{2} \mathrm{O}$ was detected, whereas in hydrated ye'elimite blended with gypsum a gel without significant water content with the formula $(\mathrm{CaO})_{0.12} \mathrm{Al}(\mathrm{OH})_{3}$ was identified. The densities of the $\mathrm{AH}_{3}$ gels were lower $\left(1.48 \mathrm{~g} / \mathrm{cm}^{3}\right.$ and 2.05 
480

481

482

483

484

485

486

487

488

489

490

491

492

493

494

495

496

497

498

499

500

501

502

503

504

505

506

507

508

509

510

511

$\mathrm{g} / \mathrm{cm}^{3}$, respectively) than for crystalline gibbsite $\left(2.40 \mathrm{~g} / \mathrm{cm}^{3}\right)$. For the density of $\mathrm{AH}_{3}$ gel in a CSA cement paste, a value of $1.5 \mathrm{~g} / \mathrm{cm}^{3}$ was found. $\mathrm{AH}_{3}$ present in CSA cements has a nano-gibbsite local structure with a particle size of 3-4 $\mathrm{nm}$ [112]. The calcium contents in the gels probably originate from intermixing with AFm phases as evidenced by HR-TEM/EDS $[107,109]$.

It has to be mentioned that the amorphous content of hydrated CSA-based systems as determined by QXRD $[12,123]$ does not only contain $\mathrm{AH}_{3}$, but also X-ray amorphous ettringite and AFm-phases as evidenced by NMR spectroscopy [123], synchrotron pair distribution function analyses [112] and mass balance calculations $[124,125]$.

The knowledge of the conditions of its formation and transformation (change in crystallinity and morphology as well as water content) is very important to understand the hydration of these systems. Recently, Hargis et al. [113] have shown experimentally that the rapid dissolution of ye'elimite is accompanied by the formation of an aluminium hydrate "gel layer" overlying the anhydrous particle. This layer serves as a point of nucleation and growth for ettringite in the surrounding space.

The polymorphism and crystallinity of aluminium hydroxide could be thus controlled by the nucleation rate, the $\mathrm{pH}$, temperature and the presence of complexing or chelating agents.

The sulphate ions in the solution have a particular impact on the nucleation and growth of aluminium hydroxide, which in turn influences its crystallization [47]. The rapid kinetics of dissolution of the ye'elimite and the high sulphate content promotes the formation of an amorphous precursor hydrate two to five times more voluminous than stoichiometric $\mathrm{AH}_{3}$ [35]. The affinity for adsorption of sulphate ions on this amorphous phase delays its crystallization. Its further polymerization and recrystallization is accompanied by the release of these sulphates [68].

Several similarities from previous CSA studies can be drawn when we consider this information. The $\mathrm{pH}$ of about 10.0 to 11.5 (down to 8.5 in the presence of some retarders [48]) favours the formation of aluminium hydroxide in its amorphous form. The rapid reaction and the presence of sulphate tend to favour this amorphous formation. Depleting the sulphates in the solution and increasing the $\mathrm{pH}$ throughout hydration would result in the crystallization of this hydrate and the formation of bayerite [126] or gibbsite [51].

\subsection{Silicate aluminate interactions}

Whether in a CSA-OPC-CS ternary system or in a BYF, the microstructure is already dense with aluminate hydrates precipitated following the reactions of ye'elimite or other aluminate phases, which are often mainly complete after 1 day of hydration. Thus, the silica-rich phases $\left(C_{2} S, C_{3} S\right.$, etc...) react in a solution that is rich in Al following the equilibrium of the latter with the aluminate-rich hydrates. The reaction of 
the silicate is generally slow and do not start and/or progress for several days or weeks $[4,127-129]$. In BYF, belite reacts in the presence of several alumina-containing hydrates and especially in the presence of aluminium hydroxide. This presence influences both the kinetics of the calcium silicate phases and the hydrate assemblage that follows their hydration. The slow kinetics and the interaction between silicate and aluminate are due to two main phenomena:

- Densification of the microstructure; similar to what observed with the reactions of SCMs at advanced ages in the OPC system, the space occupied by the water at the beginning is gradually filled by hydrates which limits further hydration [130-132].

- The solution composition and the accumulation of anions (e.g. Al) in the pore solution [48]. These elements have been known to negatively impact the reaction of silicates as observed in several studies [133-135].

The effect of pore solution composition and ions present has been discussed in several studies. The composition of the solution at later ages of hydration is close to equilibrium [93] and is largely determined by the hydrates present in the microstructure $[49,119]$.

The solubility of hydrates is lower than that of anhydrous materials. On the one hand, this allows the hydration process to occur, on the other hand, it indicates that hydrates have a more pronounced impact on the concentrations of the porous solution.

Despite the relatively high alumina concentrations, thermodynamic calculations indicate that the silicate phases are undersaturated (see Fig. 9) and therefore do not explain the low reaction kinetics of alite and belite observed in ye'elimite-rich systems. Ion species and concentrations in solution are strongly controlled by the dissolution of the silicate and by the precipitation of strätlingite and C-S-H.

The dissolution of $\mathrm{C}_{2} \mathrm{~S}$ is characterized by a solubility already among the lowest of all anhydrous systems [42]. In general, the lower the (under-)saturation, the faster the hydration is. It has been observed that calcium silicates are more undersaturated at lower amount of gypsum additions [57]. However, calcium silicate reacts with similar or slightly slower kinetics, indicating that another phenomenon is important. Additionally, during the first days of hydration in CSA systems, alite in ternary OPC CSA systems react more quickly when gypsum is added than in samples without gypsum while belite in BYF cements reacts slower when gypsum is added [57] . When analyzing the pore solution composition, the alumina concentration decreases more rapidly in gypsum systems since its concentration is controlled by the solubility of ettringite and gypsum [48]. The high concentration of alumina slows down the dissolution of calcium silicates as reported in previous studies on calcium aluminates $[135,136]$. Comparable to OPC, belite begins to react when the $\mathrm{pH}$ is high. $\mathrm{A}$ higher $\mathrm{pH}$ is reported to limit the effect of alumina of the pore 

solution on the kinetics of calcium silicate [48]. The acceleration of the reaction of belite in BYF systems is

545 always correlated with the crystallization and the consumption of aluminium hydroxide that it is leading 546 to the decreasing concentration of alumina in the pore solution. This in its turn increases the $\mathrm{pH}$ and 547 improves the reactivity of belite at a later age [48].

548
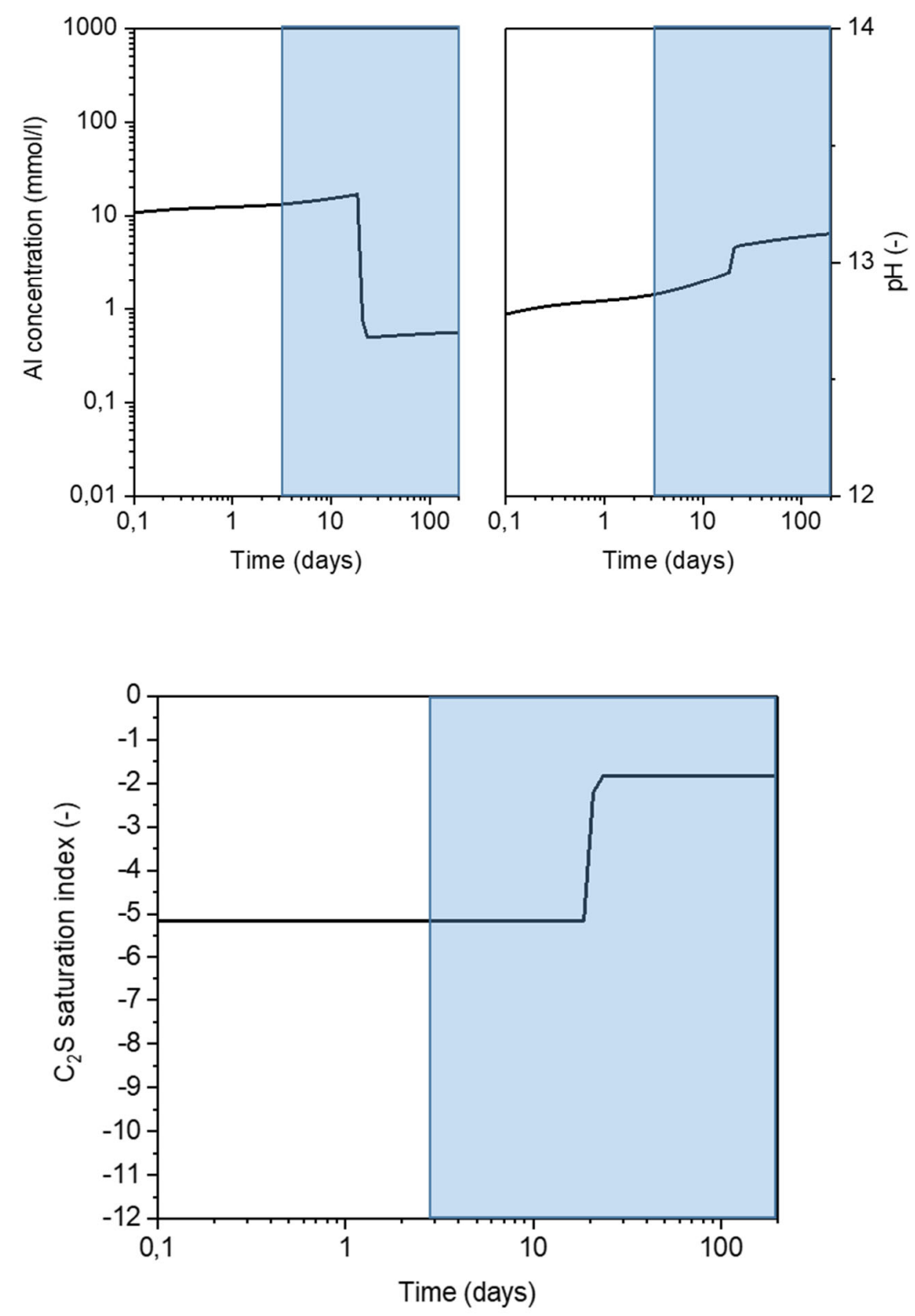

549

550 Fig. 9 Evolution of a) Al concentration, pH, and b) saturation indices of belite over time for a BYF

551 system (dark grey zone: belite starts to react). Adapted from [134]. 
Other silicate phases besides belite contribute to the long-term hydration reactions. Ternesite $\left(C_{5} S_{2} \bar{S}\right)$, which may form when excess anhydrite is present in the raw meal [127], is generally considered to be an inert phase, however it is able to hydrate in the presence of $\mathrm{AH}_{3}$ or calcium (sulpho)aluminates to form strätlingite $[57,127,137]$ and calcium sulphate. The latter is available for further hydration reactions, i.e. ettringite formation from ye'elimite. It was found that ternesite is more reactive than $B-C_{2} S[15,127]$. Fluorellestadite $\left(\mathrm{C}_{9} \mathrm{~S}_{3} \overline{\mathrm{S}}_{3} \cdot \mathrm{CaF}_{2}\right)$ may be present in CSA clinkers when a mineralizer containing fluorine was used or the raw materials (e.g. fluorogypsum) contained significant amounts of fluoride $[23,138]$. This phase is hydraulically active as well, and its reactivity exceeds as well the one of $B-C_{2} S[23,100]$. Gehlenite $\left(C_{2} A S\right)$, which may form in significant amounts in laboratory and also industrial clinkers, is not fully inert as well. Like in calcium aluminate cements [139], some gehlenite might react and form strätlingite on the longterm [140].

563 In addition to strätlingite also other hydrates form besides ettringite, monosulphate and $\mathrm{AH}_{3}$. Calcium 564 silicate hydrates C-S-H occur at high belite contents and/or belite hydration degrees $[76,141]$, but is challenging to identify especially if it occurs in low amounts [138]. $\mathrm{CAH}_{10}$ may form at early age in CSA clinkers and CSA cements with low contents of calcium sulphate (generally anhydrite) as explained previously, and disappears at later hydration times [76]. Hydrogarnet, often incorporating iron and silicium, which forms at ambient temperatures only in the long-term [142,143], can be found at temperatures of $40^{\circ} \mathrm{C}$ and above already at hydration times of 28 days and even earlier $[144,145]$. Selective extraction using salicylic acid/methanol can be used to improve the identification of siliceous

571 hydrogarnet [146].

\section{$572 \quad 3.7 \quad$ Impact of retarders}

573 Cement hydration can be delayed in two ways: by inhibiting the dissolution of one or more reactive solids 574 or by inhibiting hydrate precipitation.

575 According to the retardation of CSA in the literature, the exact and detailed mechanisms of hydration inhibition cannot be clearly identified. However, the main means of retardation can be grouped whether the retarder mainly inhibits clinker dissolution or hydrate precipitation. 

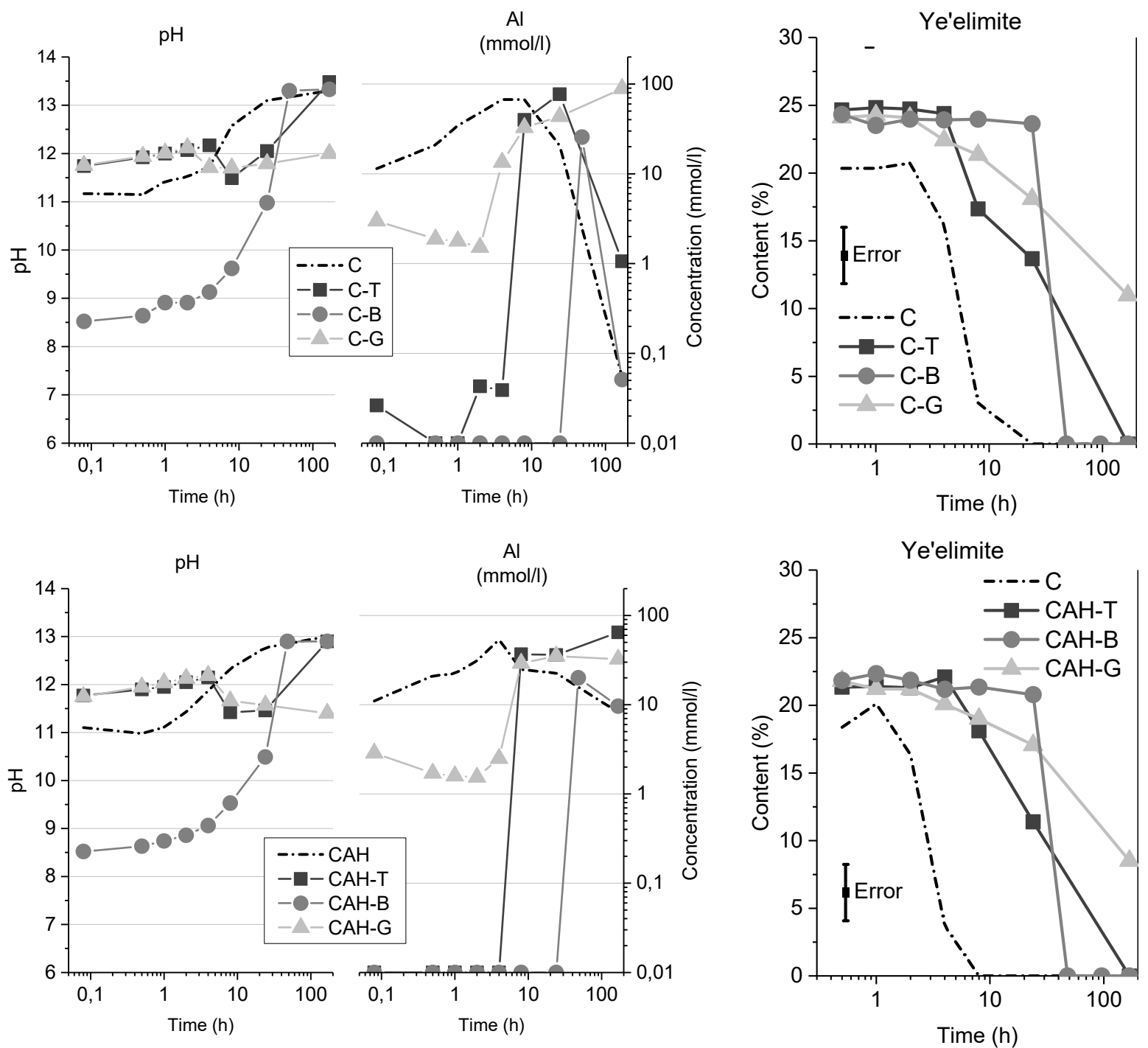

Fig. 10 Effect of retarders on $\mathrm{pH}$ and $\mathrm{Al}$ concentration in pore solution and ye'elimite reaction. C: BYF clinker, CAH: BYF clinker + microanhydrite, T: Tartaric acid, B, Sodium borate, G: Sodium gluconate at W/C =2. Adapted from [48].

\subsubsection{Fruit acids}

Fruit acids are known calcium chelating ligands whose resulting complexes are poorly soluble in water. Comparing calcium concentrations of samples with fruit acids to reference ones, a significantly higher concentration is found. However, chelating alone cannot be the only cause of delay. This type of retarder must also ensure a certain affinity to aluminium. The increase of $\mathrm{pH}$ as well can destabilize the retarder chelating compounds and reaccelerate the reaction. $\mathrm{pH}$ values above 11.5, for example are reported to dissolve the complexes formed with aluminate and to release $\mathrm{Al}(\mathrm{OH})_{4}{ }^{-}$in the solution [147]. 
The limited results on CSA systems lead us to make parallels with other aluminate-based systems. The mechanisms of $C_{3} A$ reaction retardation by tartrate have been described in the literature [148]. The acids adsorb directly to the surface of the $\mathrm{C}_{3} \mathrm{~A}$ and block its reaction with water. The mechanism involves chelating calcium with tartaric acid followed by precipitation of a layered calcium tartrate that covers the surface of the $C_{3} A$ grains, thus inhibits further hydration.

Fruit acids inhibit the nucleation and growth of ettringite [89]. Knowing that ettringite can adsorb large amounts of negatively charged polycarboxylate superplasticizers [149], and knowing that the fruit acids used are generally negatively charged, these acids could thus adsorb on ettringite surfaces and block its growth. Indeed, the results presented by Zajac et al. [48] show that the growth of ettringite is inhibited, which leads to oversaturation of the pore solution with respect to ettringite without being able to observe any precipitation (see Fig. 10). Consumption by absorption in the volume or adsorption on the surface of the hydrates slows down the reaction. Once the retarder is consumed, the kinetics of the reaction reaccelerates as in the case of non-retarded samples.

\subsubsection{Borate compounds}

A low $\mathrm{pH}$ of the cement pore solution is observed when adding borates generally associated with the presence of $\mathrm{B}(\mathrm{OH})_{4}{ }^{-}$species in the cement pore solution. Boric acid is a weak acid in water, with a very limited solubility at $25^{\circ} \mathrm{C}$. The mononuclear species $\mathrm{B}(\mathrm{OH})_{3}$ and $\mathrm{B}(\mathrm{OH})_{4}{ }^{-}$are present and are generally the most abundant present in the solution. Polyborates occur only at boron concentrations above $1 \mathrm{~g} / \mathrm{l}$. In cement solution generally with a $\mathrm{pH}$ greater than $9, \mathrm{~B}(\mathrm{OH})_{4}{ }^{-}$is dominant [150].

If sodium borate is used as retarder, the precipitation of the mineral called dawsonite $\left(\mathrm{NaAlCO}_{3}(\mathrm{OH})_{2}\right)$ has been reported and suggested by Zajac et al. [48]. This mineral is known in CAC cements exposed to an alkaline environment [151]. However, this phase may only be a metastable phase that captures alkaline ions keeping the $\mathrm{pH}$ of the solution low. Borate ions, on the other hand, which are quickly and partially depleted from the solution, could precipitate into two hydrates: (i) ulexite $\mathrm{CaNa}\left[\mathrm{B}_{5} \mathrm{O}_{6}(\mathrm{OH})_{6}\right] \cdot 5 \mathrm{H}_{2} \mathrm{O}$ with a very low crystallinity, which forms transiently during the period of low thermal activity, and (ii) inyoite $\mathrm{Ca}\left(\mathrm{H}_{4} \mathrm{~B}_{3} \mathrm{O}_{7}\right)(\mathrm{OH})_{4} \mathrm{H}_{2} \mathrm{O}$, a calcium borate phase $[78,80]$. In borate systems and due to the low $\mathrm{pH}$, almost no dissolution of ye'elimite is reported suggesting that the retardation is mainly driven by inhibiting the dissolution of the reactive anhydrous phases (see Fig. 10). The process by which dissolution is inhibited is not clear.

\subsubsection{Sugars}

Sugars are the most effective hydration inhibitors of cements. Based on several results from different studies, it has been hypothesized that the adsorption of saccharides on hydrating minerals contributes to 
their effectiveness in slowing hydration [152,153]. However, there is no clear explanation of the exact mechanism of sugar delay on aluminate systems. The work of Smith et al. [154,155] shows that carboxylate glucose reacts with the -Al(OH) groups of calcium aluminium hydrates. This indicates a strong adsorption of saccharinic acids on aluminium hydration products. Gluconate ion inhibits $\mathrm{Al}(\mathrm{OH})_{\mathrm{x}}$ precipitation, and it may block gibbsite growth $[71,72]$. This in its turn inhibits the growth of ettringite and monosulphate, resulting in high oversaturation of these phases.

\subsection{Effect of sulphate additions}

The type of calcium sulphate added does not influence the long-term stable hydrate assemblage, but influences hydration kinetics, and thus the time when certain hydrates appear, see e.g. $[49,73,140,156-$ 159]. While hemihydrate and gypsum are dissolving fast in CSA systems, some anhydrites may show a quite slow hydration kinetics and can still be detected by XRD after 28 days of hydration [140]. The incomplete hydration of anhydrite decreases the amount of ettringite after $28 \mathrm{~d}$ compared to a sample where only gypsum was used as calcium sulphate addition. This reduced amount of ettringite leads to a lower volume of hydrates and thus to a lower compressive strength. Blending a low amount of gypsum with an anhydrite of poor reactivity may enhance the dissolution of anhydrite and thus improve compressive strength [140]. When the calcium sulphate phases reached almost full hydration, often longterm strengths are often higher when anhydrite instead of gypsum is used and almost complete hydration has been reached $[115,159]$, but also the opposite effect is reported in literature [76].

The amount of calcium sulphate added to the CSA clinker retards the dissolution kinetics of belite and thus also the kinetics of strätlingite formation $[76,160]$, which is the primary product of belite hydration in CSA cements, see experimental data in e.g. $[49,142,158,161]$ and thermodynamic calculations $[76,141]$. This is highlighted in Fig. 11 showing the phase development of a CSA hydrated with different additions of gypsum [160], comparing Fig. 11b (lower amount of gypsum added) with Fig. 11c (higher amount of gypsum added). There might be several reasons for this behaviour. Firstly, the more calcium sulphate is added, the more ettringite forms, the higher is the volume of hydrates and the lower the amount of available water and available space to grow hydrates. Secondly, the pore solution of CSA cements containing belite is high in aluminium as long as calcium sulphate is present, and decreases, when the calcium sulphate is depleted $[49,100]$. It is known from literature, see e.g. [162-164], that Al present in the pore solution delays the hydration of calcium silicates. Thirdly, strätlingite is not a thermodynamic stable stable phase in the presence of calcium sulphate $[76,141]$. 
650

651

652

653

654

655

656

657

658

659

660

661

662

663

664

665

666

667

668

669

670

671

672

673

674

675

676

677

\subsection{Effect of $w / c$ ratio and temperature}

For complete hydration of CSA-based systems higher $\mathrm{w} / \mathrm{c}$ ratios are needed than for Portland cements. Pure ye'elimite blended with 2 molar equivalents of anhydrite needs a w/c of 0.78 for complete hydration [165]. For technical CSA cements values increase with increasing amount of anhydrite added and are in the order of 0.35-0.60 [166]. Lura et al. [167] investigated the hydration of a CSA cement using various $\mathrm{w} / \mathrm{c}$ between 0.40 and 1.50 by means of isothermal calorimetry. They observed that the cumulative heat after $7 \mathrm{~d}$ of hydration increases strongly with increasing $\mathrm{w} / \mathrm{c}$ up to a w/c of 0.75 , while this increase gets remarkably slower beyond a $\mathrm{w} / \mathrm{c}$ of 0.75 . Based on their results they suggested a calorimetric method to estimate the water demand (chemically and physically bound water) of CSA cements.

If the $\mathrm{w} / \mathrm{c}$ ratios applied are below the water demand needed for complete hydration, self-desiccation occurs, and especially the hydration degrees of the slower reacting phases (i.e. belite, ferrite) remain quite low $[142,160,166]$. This is illustrated in Fig. 11, where the phase development of a CSA hydrated at w/c 0.80 (Fig. 11b) is compared to the phase development at w/c 0.40 (Fig. 11a) [160]. Ye'elimite and especially belite reach at w/c 0.80 much higher hydration degrees after $28 \mathrm{~d}$ than at $w / c 0.40$. This results in higher ettringite contents and a significant formation of crystalline strätlingite at the higher $\mathrm{w} / \mathrm{c}$ ratio after 28 days. Furthermore the use of low $\mathrm{w} / \mathrm{c}$ ratios leads to hydrated pastes with a very low porosity and permeability, see $[100,142,168-172]$.

Hydration temperature influences hydration kinetics, but also the type of hydrate phases formed $[144,145]$. $\mathrm{CAH}_{10}$ occurs at low to moderate temperatures (up to approximately $40^{\circ} \mathrm{C}$ ), especially in CSA clinkers. In water-saturated conditions, ettringite in CSA remains stable until about $90^{\circ} \mathrm{C}$; then it decomposes to monosulphate and calcium sulphate. Thus, CSA-based materials, which were subjected in water saturated conditions to temperatures of $90^{\circ} \mathrm{C}$ and higher, will undergo a delayed ettringite formation leading to severe expansion [144]. However, if hydrated CSA is heated to $80^{\circ} \mathrm{C}$ and higher at low relative humidity, ettringite decomposes to meta-ettringite which contains only 9-13 moles of crystal water instead of the usual 30-32 $[84,173,174]$. This dehydration process is associated with a high enthalpy of 600-800 J/g $[173,175,176]$ and is reversible. Thus hydrated CSA cements are suggested as a suitable material for seasonal heat storage $[144,173,175,177-179]$. 

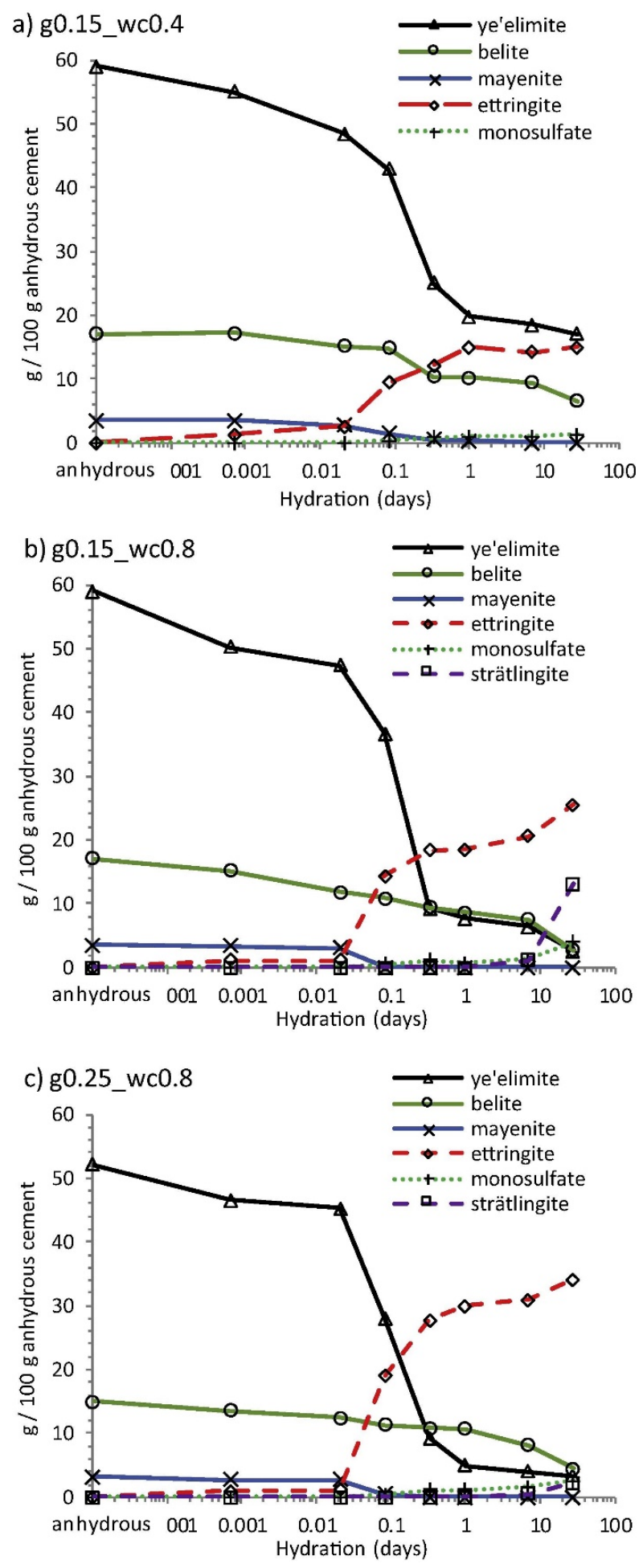

Fig. 11.: QXRD results for a CSA clinker containing 69 mass-\% ye'elimite and 20 mass-\% belite a) blended with 15 mass-\% gypsum and hydrated at w/c 0.40 (g0.15_wc0.4), b) blended with 15 mass-\% gypsum and hydrated at w/c 0.80 (CSAB_g0.15_wc_0.8), and c) blended with 25 mass-\% gypsum and hydrated at w/c 0.80 (CSAB_g0.25_wc0.8). 

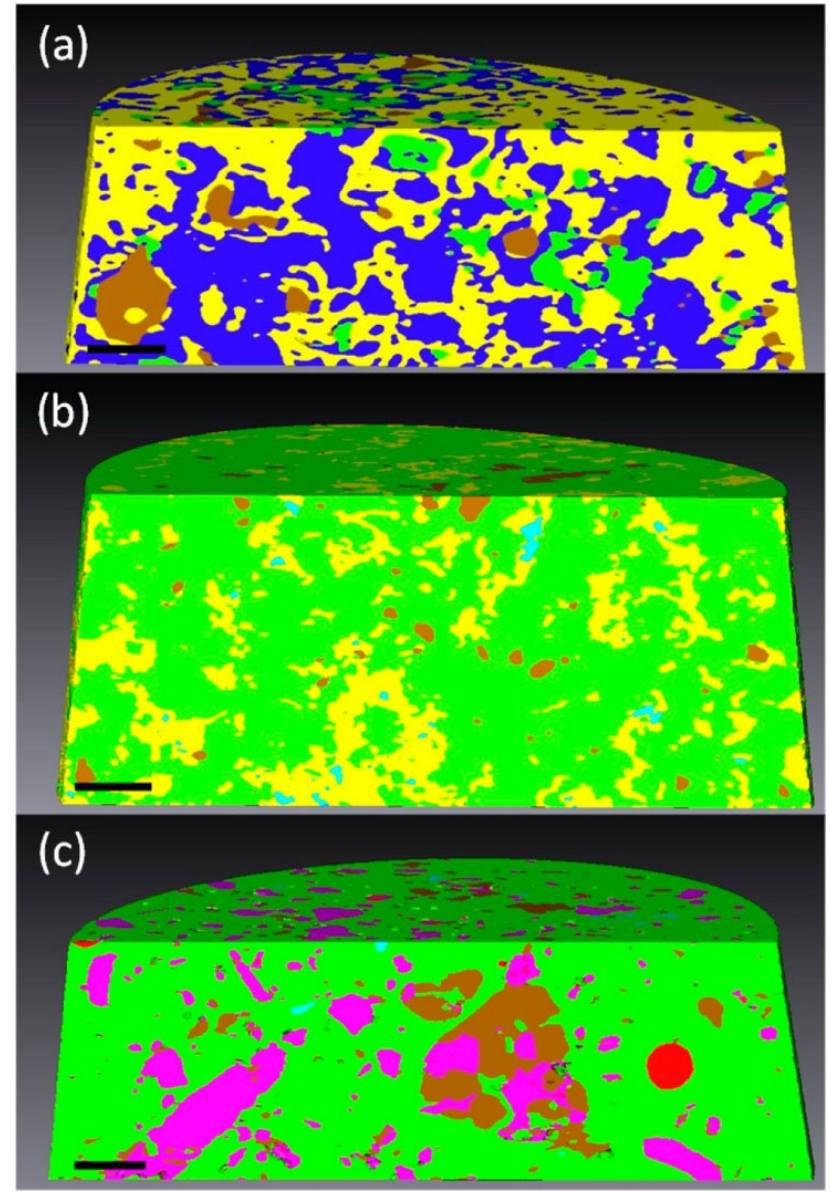

Fig. 12.: Three-dimensional renderings of the segmented volumes derived from Ptychographic X-ray Computed Tomography showing the components for (a) ye'elimite paste after 8 days of hydration; (b) ye'elimite-gypsum (molar ratio 1:2) paste after 18 days of hydration; and (c) CSA paste (CSA clinker containing 72 mass-\% ye'elimite blended with 25 mass-\% anhydrite) after 22 days of hydration. Colour codes: for hydrated phases, dark blue-AFm, green-AFt, yellow-A-H gel; for anhydrous phases, brown-ye'elimite (and gypsum), purple- $\mathrm{Ca}_{2} \mathrm{SiO}_{4}$, pink-MgO; for porosity, light blue-water porosity, red-air. For CSA paste, AFt and A-H gel are segmented together (green). Scale bar $=\mathbf{5} \boldsymbol{\mu m}$. Taken from [109]. Copyright needed

\section{Thermodynamics modelling of hydrated ye'elimite-based systems}

\subsection{Thermodynamic principles}

694 Thermodynamic equilibrium calculations, see recent review articles focussed on modelling of 695 cementitious systems [93,141,180-182] and references cited therein, predict the composition of a system 696 composed of aqueous, solid and gaseous phases at the temperature and pressure of interest. Such 697 calculations require a geochemical speciation software such as GEMS or PhreeqC and are based on the 698 relative stability of the different hydrates and aqueous species using sets of thermodynamic data 699 compiled in thermodynamic databases containing thermodynamic data for all relevant solid, aqueous and 700 gaseous species, see e.g. [94,183,184]. 
Thermodynamic modelling of the composition of hydrated cements are based on the composition and amount of reacted anhydrous material using thermodynamics to predict which hydrates are the most stable under the conditions investigated. In cement science, it can help to understand on a chemical level the consequences of factors such as cement composition, hydration, interaction with salt solution or gases, leaching, or temperature on the composition and the properties of a hydrated cementitious system. The stable hydrate phases can be calculated for fully hydrated systems or based on the chemistry of the pore solution. Hydration kinetics can be implemented by restricting the dissolution of the anhydrous phases with time which allows following the changes of solid phases and pore solution chemistry during hydration. As precipitation processes can be slow, thermodynamic equilibrium may not always be reached, thus it is important to compare the modelling results with experimental data, as determined e.g. by X-ray diffraction, thermogravimetry or analyses of the pore solution composition.

\subsection{Basic hydration reactions of ye'elimite}

The simplified hydration reaction of pure ye'elimite is shown in Equation 2 below resulting in the formation of monosulphate together with aluminium hydroxide. Lately the formation of monocalcium aluminate hydrate $\left(\mathrm{CAH}_{10}\right)$, a metastable phase, during the early hydration period of synthetic ye'elimite was reported according to Equation $3[47,68,76,113,143]$.

$$
\text { Equation } 2 \quad C_{4} A_{3} \bar{S}+18 H \rightarrow C_{4} A \bar{S} H_{12}+2 A_{3}
$$

$$
\text { Equation } 3 \quad 3 \mathrm{C}_{4} \mathrm{~A}_{3} \overline{\mathrm{S}}+\mathbf{9 8} \mathrm{H} \rightarrow \mathrm{C}_{6} \mathrm{AS}_{3} \mathrm{H}_{32}+2 \mathrm{CAH}_{10}+2 \mathrm{AH}_{3}
$$

Wang [185] speculated that in the absence of calcium sulphate ettringite and katoite may be formed together with aluminium hydroxide according to Equation 4. This assumption is supported by the findings of Song et al. [107].

$$
\text { Equation } 4 \quad \mathbf{3 C}_{4} \mathrm{~A}_{3} \overline{\mathrm{S}}+62 \mathrm{H} \rightarrow \mathrm{C}_{6} \mathrm{~A}_{\mathbf{S}_{3}} \mathrm{H}_{32}+2 \mathrm{C}_{3} \mathrm{AH}_{6}+6 \mathrm{AH}_{3}
$$

The formation of other calcium aluminate hydrates such as $\mathrm{C}_{3} \mathrm{AH}_{6}, \mathrm{C}_{4} \mathrm{AH}_{\mathrm{x}}$ beside $C A H_{10}$ are reported in hydrated ye'elimite cements $[76,107,186]$. These are not considered in these idealized equations. Thermodynamic modelling predicts stable ones like $C_{3} A H_{6}$ [76,187].

The addition of calcium sulphate promotes the formation of ettringite over monosulphate as presented in a simplified form in Equation 5 with a rate depending on the rate of the calcium sulphate dissolution $[115,156]$.

$$
\text { Equation } 5 \quad C_{4} A_{3} \bar{S}+2 C \bar{S} H_{2}+34 H \rightarrow C_{6} A \bar{S}_{3} H_{32}+2 A_{3}
$$

If the amount of added calcium sulphate is less than that required for the full reaction with ye'elimite, monosulphate will form after the depletion of sulphate. This reaction could be described in a simplified way in Equation 6. 
Equation $6 \quad \mathrm{C}_{4} \mathrm{~A}_{3} \overline{\mathrm{S}}+\mathbf{C} \overline{\mathbf{S}} \mathrm{H}_{2}+26 \mathrm{H} \rightarrow 0.5 \mathrm{C}_{6} \mathrm{AS}_{3} \mathrm{H}_{32}+0.5 \mathrm{C}_{4} \mathrm{~A} \overline{\mathbf{S}} \mathrm{H}_{12}+2 \mathrm{AH}_{3}$

\section{4 \\ 4.3 Thermodynamics in ye'elimite systems}

735 In the recent years, thermodynamic modelling related to systems based on CSA cements has been increasingly used to calculate ye'elimite resp. CSA clinker and calcium sulphate $[5,13,14,23,51,68]$, the influence of belite content on the hydration products $[13,14,19]$, the amount of supplementary cementitious materials added such as limestone [76,141,188-190], fly ash [138] or metakaolin [191], or the blending with Portland cement [128,188] or hydrated lime [192].

- $\quad$ Solid phase changes of CSA $[49,57,100,140,142,160]$ and CSA blended with OPC and calcium sulphate $[129,190]$ depending on hydration kinetics; kinetics is derived from QXRD and other methods such as NMR and generally fitted with empirical equations.

- Saturation indices of hydrate phases based on the composition of the pore solution of CSA $[49,57,100]$ and CSA blended with Portland cement and calcium sulphoaluminate $[124,129,193,194]$.

- Interaction of hydrated CSA-based systems with $\mathrm{CO}_{2}$ to assess phases changes due to carbonation $[172,195,196]$.

- Recently, It has been used to explain the early hydration of ye'elimite phase $[35,60]$

The $\mathrm{CaO}-\mathrm{Al}_{2} \mathrm{O}_{3}-\mathrm{SiO}_{2}-\mathrm{CaSO}_{4}-\mathrm{H}_{2} \mathrm{O}$ (and thus its sub-system $\mathrm{C}_{4} \mathrm{~A}_{3} \overline{\mathrm{S}}-\mathrm{C}_{2} \mathrm{~S}-\mathrm{C} \overline{\mathrm{S}}-\mathrm{H}_{2} \mathrm{O}$, which is relevant for CSA cements) system was explored by thermodynamic calculations by Damidot et al. $[197,198]$ using the stateof-the-art databases available at that time. Recently, a new version of the CEMDATA thermodynamic database (CEMDATA 18) was published [94], which covers thermodynamic data for most of the clinker and hydrate phases relevant for CSA cements such as ettringite and AFm-phases and their solid solutions, aluminium hydroxide in various states of crystallinity, $\mathrm{C}-\mathrm{S}-\mathrm{H}$, and $\mathrm{C}-\mathrm{A}-\mathrm{H}$-phases. In the recent version, also hydrates such as ettringite and AFm-phases with lower content of crystal water are included [82-84], allowing the modelling of hydrated CSA cements at relative humilidies below $100 \%$.

Recently, the stable phases in the system $\mathrm{C}_{4} \mathrm{~A}_{3} \overline{\mathrm{S}}-\mathrm{C}_{2} \mathrm{~S}-\mathrm{C} \overline{\mathrm{S}}-\mathrm{H}_{2} \mathrm{O}$ were re-calculated $[76,141]$ using GEMS coupled with the Nagra/PSI database and the cement-specific CEMDATA database. Fig. 13 presents the phase assemblages for the ternary blend of the anhydrous phases at a fixed value of anhydrite/ye' elimite $=15 / 85$ by mass (molar ratio 0.8 ). With increasing replacement of ye'elimite by belite, strätlingite forms and $\mathrm{Al}(\mathrm{OH})_{3}$ is consumed. Ettringite and strätlingite are no longer stable at replacement levels beyond $60 \%$ and $80 \%$, respectively, while $\mathrm{C}-\mathrm{S}-\mathrm{H}$ and monosulphate are stabilized due to the availability of 
765

766

767

768

769

770

771

772

773

774

775

776

777

778

779

780

781

782

783

784

785

786

787

788

789

790

791

792

793

794

795

796

sufficient calcium oxide from belite. Katoite and portlandite occur beyond approximately $75-80$ mass-\% belite.

More trends can be seen if the quantities of the hydrate phases are plotted in a ternary diagram $C_{4} A_{3} \bar{S}$ $\mathrm{C}_{2} \mathrm{~S}-\mathrm{C} \overline{\mathrm{S}}$. Ettringite (Fig. 14a) is stable in almost the entire range of the ternary system with the exception of a small region with high belite contents and very low calcium sulphate contents. Maximum ettringite contents are located around 20-40 mass-\% ye'elimite, 20-40 mass-\% belite and 40-50 mass-\% anhydrite. C-S-H contents decrease towards lower belite contents (Fig. 14b) and C-S-H is absent in the region with both low belite ( $<30$ mass-\%) and low anhydrite (<30 mass-\%) contents. Under these conditions, the silica provided by the belite gets incorporated into strätlingite (Fig. 14c). Strätlingite is present only at low anhydrite contents, and does not occur at high belite contents, as it is not stable in the presence of excess calcium sulphate or portlandite. The total volume of hydrates (Fig. 14d is strongly related to the amount of ettringite in the hydrate assemblage, as ettringite is the phase incorporating the highest amount of water among the hydrates present in the system. From these calculations of the hydrates occurring in the ternary system $\mathrm{C}_{4} \mathrm{~A}_{3} \overline{\mathrm{S}}-\mathrm{C}_{2} \mathrm{~S}-\mathrm{C} \overline{\mathrm{S}}-\mathrm{H}_{2} \mathrm{O}$, a phase diagram showing the 12 different stable phase assemblages can be derived [76].

The calculations of the stable phase assemblages can be combined with equations describing the dissolution kinetics of the anhydrous clinker phases. Thus, the phase changes of CSA-based systems during hydration can be modelled as shown in Fig. 15a. Ye'elimite and gypsum are modelled to dissolve rapidly, while ettringite, monosulphate and $\mathrm{AH}_{3}$ are calculated as stable hydrate phases. The silicate containing phases belite and fluorellestadite dissolve much slower and to a lower extent, leading to the formation of strätlingite.

Also the interaction of CSA cements with supplementary cementitious systems can be modelled as shown in Fig. 15b with fly as ash as an example, which is proven to show some reactions in CSA-based systems [138]. With increasing reaction degree of fly ash the modelled phase assemblage changes, as strätlingite is formed on the expenses of monosulphate as the amount of dissolved silica from the fly ash increases. At fly ash reaction degrees above $35 \%$ C-S-H forms, which was also confirmed experimentally.

\subsection{Limitations of thermodynamics}

As thermodynamic modelling calculates the stable phases, metastable phase assemblages cannot be easily covered. One major example is the occurrence of $\mathrm{CAH}_{10}$ preferably in systems with a low ratio of calcium sulphate to ye'elimite (especially when an anhydrite with low reactivity is used). $\mathrm{CAH}_{10}$ forms mainly between 1 and 3 days of hydration, and starts to decompose beyond 28 days at ambient temperatures $[47,199]$. It has to be noted that it is stable in CSA systems at temperatures below $20^{\circ} \mathrm{C}$ 
[144]. $\mathrm{CAH}_{10}$ forms directly from the hydration of ye'elimite together with ettringite and aluminium hydroxide according to Equation 3, which is an alternative reaction path to the formation of monosulphate and aluminium hydroxide (Equation 2).

800 The occurrence of $\mathrm{CAH}_{10}$ is linked to the solubility of $\mathrm{AH}_{3}$, which decreases with time due to an increase 801 of its crystallinity as highlighted in Fig. 7 [94,100,199,200]. In Equation 3, 2 moles of $\mathrm{AH}_{3}$ are formed per 802 mol of ye'elimite, whereas in Equation 2, only 0.67 moles of $\mathrm{AH}_{3}$ are formed per mol ye'elimite. Thus in 803 case of a highly soluble $\mathrm{AH}_{3}$ occurring at early hydration times, the reaction according to Equation 2 would 804 be thermodynamically more favourable than the reaction according to Equation 3 , as the very stable 805 phase ettringite is formed together with less $\mathrm{AH}_{3}$. The very early occurrence of $\mathrm{CAH}_{10}$ already after a few 806 minutes of hydration was recently evidenced by [47]. At later ages, when $\mathrm{AH}_{3}$ becomes less soluble and 807 thus more stable, ettringite and $\mathrm{CAH}_{10}$ are destabilized in favour of monosulphate (see Fig. 16).

808 Another well-known case of metastability is the occurrence of hemicarbonate in CSA cements blended 809 with limestone instead of the more stable monocarbonate, which is calculated to form $[189,190]$. The 810 formation of hemicarbonate instead of monocarbonate is observed as well in hydrated Portland cements 811 [201] and could be related either to a slow limestone dissolution kinetics or to a faster formation of 812 hemicarbonate compared to monocarbonate. A recent study [202] revealed that in the case of Portland 813 cements the faster formation kinetics of hemicarbonate compared to monocarbonate seems to be the 814 main influencing factor.

815 Regarding thermodynamic modelling of CSA-based systems still some gaps are existing. There are several 816 thermodynamic datasets for ye'elimite available in literature [32,203-205], which need to be critically 817 reviewed before including a consistent data set into thermodynamic databases. Such data would be 818 needed e.g. for calculating the hydration heat flow and the heat of hydration of ye'elimite-based systems, 819 similar as previously done for Portland cement [206]. While thermodynamic data for ternesite was 820 recently determined [41,205], such data seems to be missing for fluorellestadite.

821 Also the composition of C-S-H in hydrated CSA, which is expected to form at high belite reaction degrees, 822 is not known. It can be hypothesized that such C-S-H would have a low $\mathrm{Ca} / \mathrm{Si}$ ratio and would contain 823 significant amounts of aluminium as in the case of hydrated Portland cement blended with Al-containing 824 SCMs, see e.g. [207]. Currently the composition of C-S-H in CSA cements, especially the Al-intake, cannot 825 be modelled properly as a thermodynamic model for C-A-S-H is ongoing research even for (blended) 826 Portland cement [94]. 


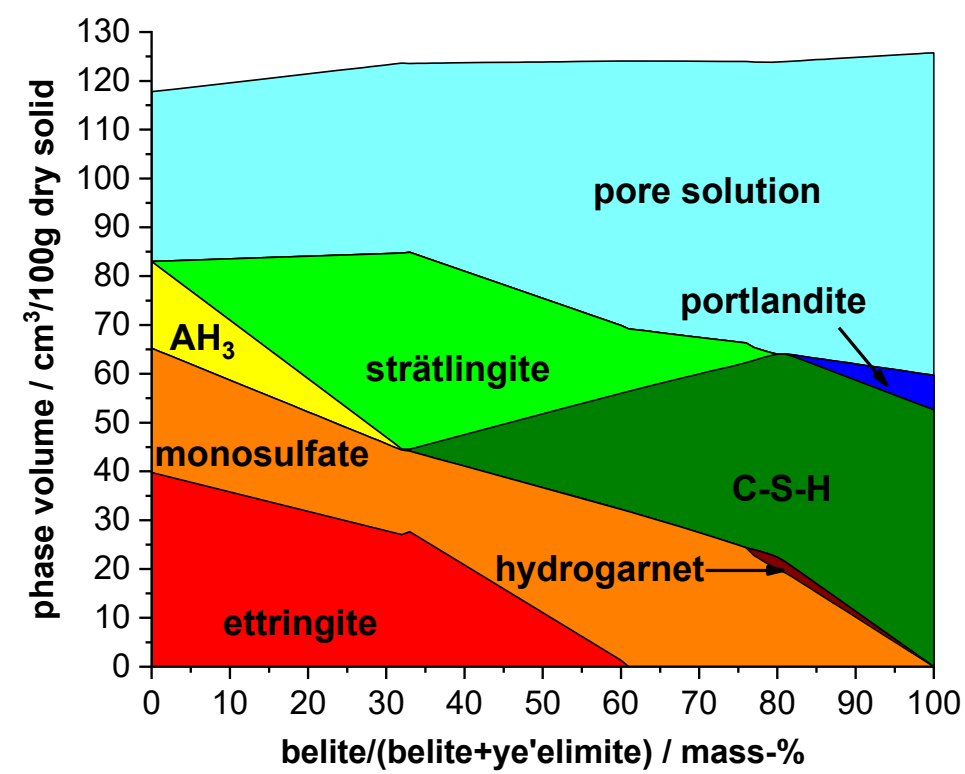

Fig. 13.: Calculated phase diagram of the thermodynamic stable hydrate assemblages of the system ye'elimite calcium sulphate - belite - water at a fixed molar ratio anhydrite / ye'elimite of 0.8 (anhydrite / ye'elimite = 15:85 by mass) using a w/c of 1 allowing complete hydration. Taken from [76] . Copyright needed

a)

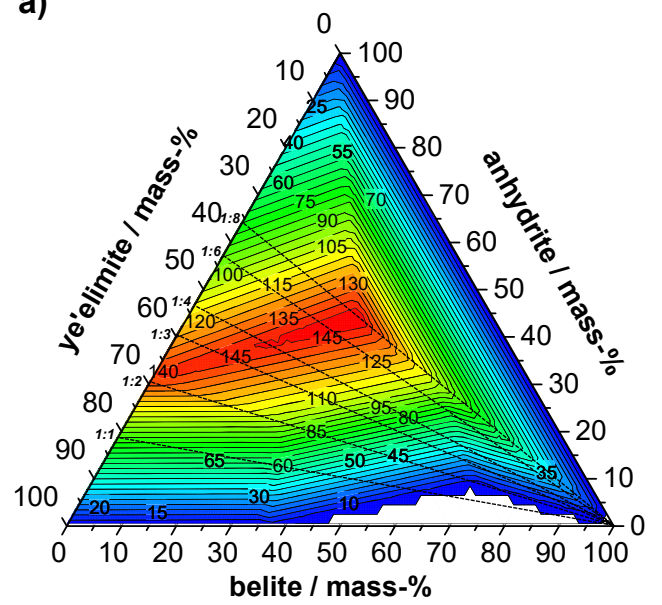


b)

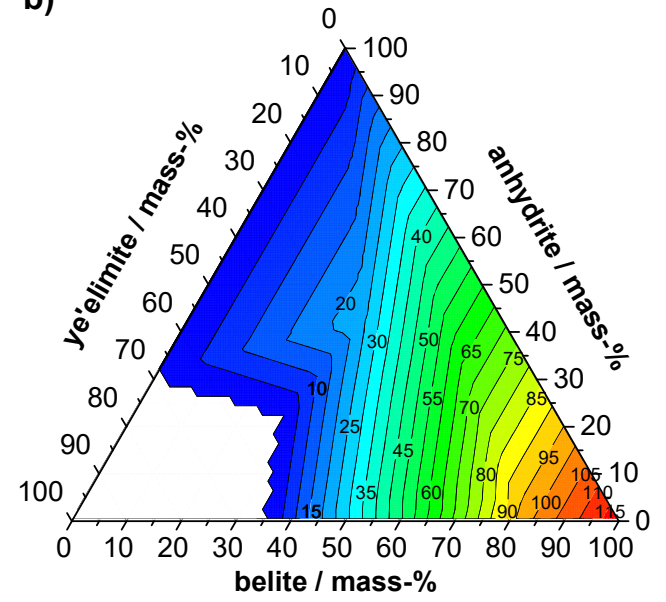

C-S-H

g/100g

834

c)

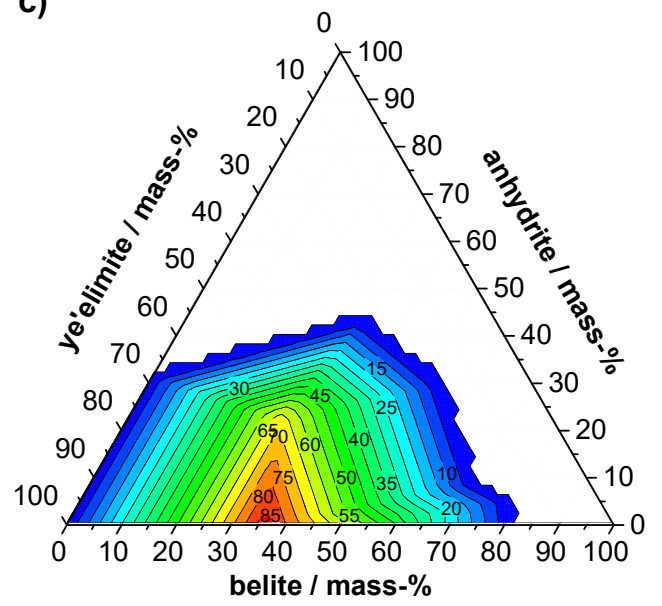

Strätlingite $\mathrm{g} / 100 \mathrm{~g}$

835

d)

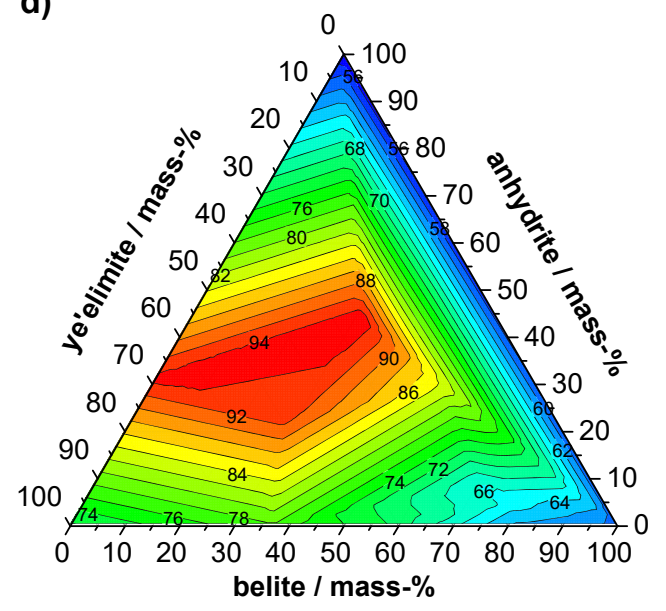

Hydrates $\mathrm{cm}^{3} / 100 \mathrm{~g}$

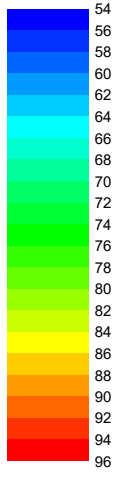


Fig. 14.: Ternary diagram $C_{4} A_{3} \bar{S}-C_{2} S-C \bar{S}$ at $20^{\circ} C$, a) ettringite, b) C-S-H, c) strätlingite contents, and d) total volume of hydrates in $\mathrm{cm}^{3}$ per $100 \mathrm{~g}$ unhydrated solid. The dotted lines in Fig. 14a represent different molar ratios between ye'elimite and anhydrite. Taken from [76,140].

a)

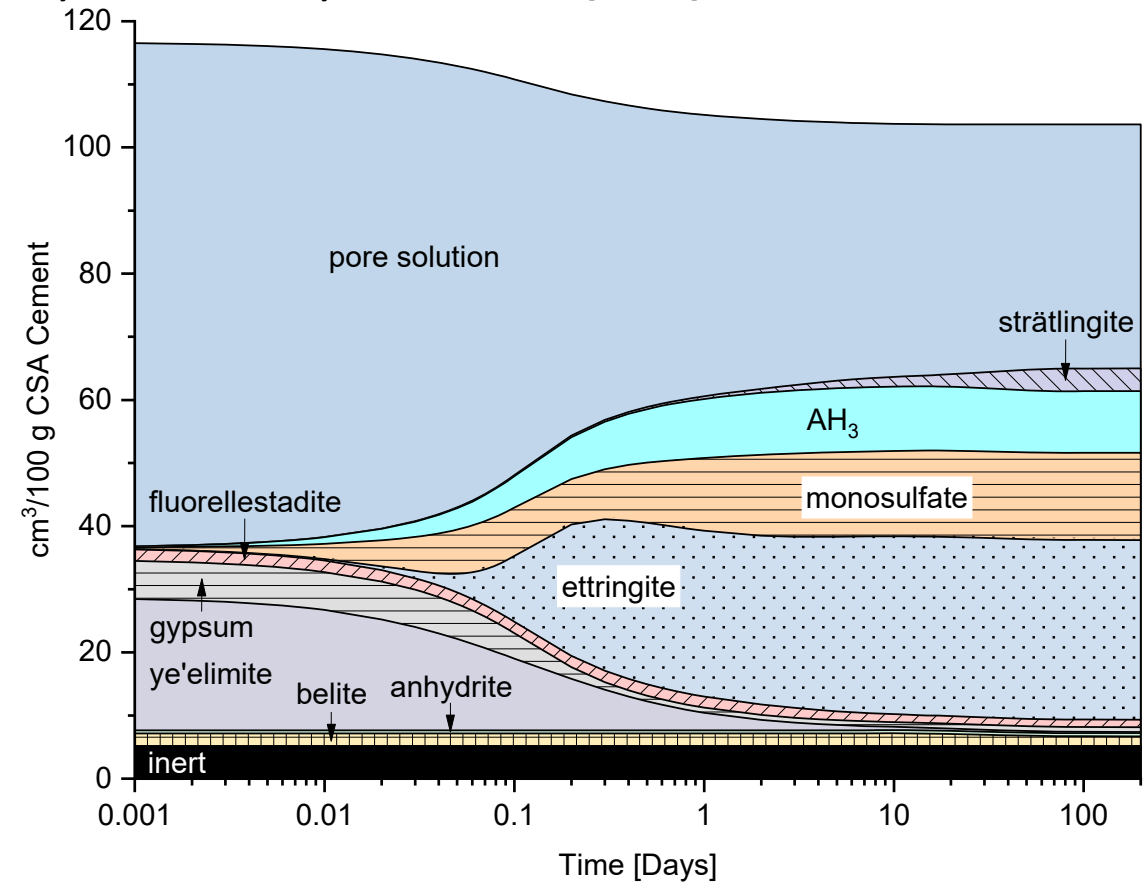

b)

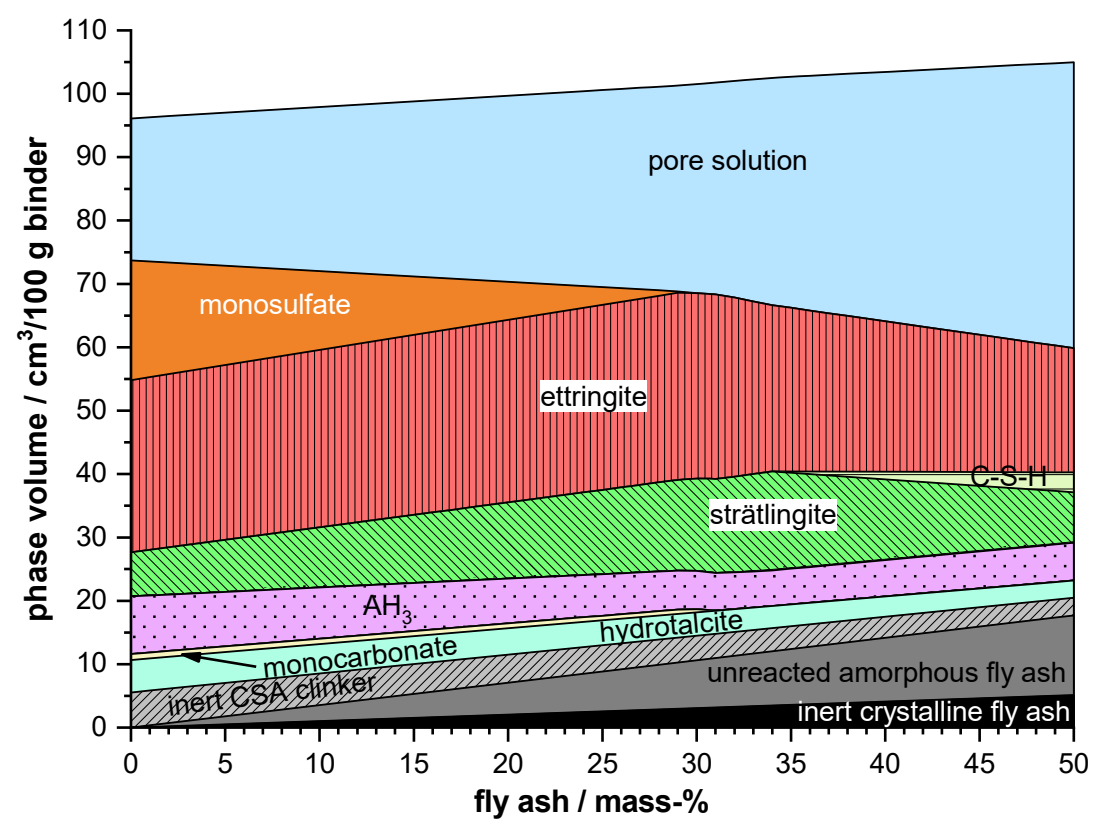

fly ash / mass-\%

842 Fig. 15. a) Thermodynamic modelling of CSA cement hydration over time (taken from [100]), b)

843 Calculated hydrate assemblages of a CSA-cement / fly ash blend ( $55 / 45$ by mass) as a function of fly ash

844 reaction degree (adapted from [138]). Copyright needed for a) 
- Capmas 1989
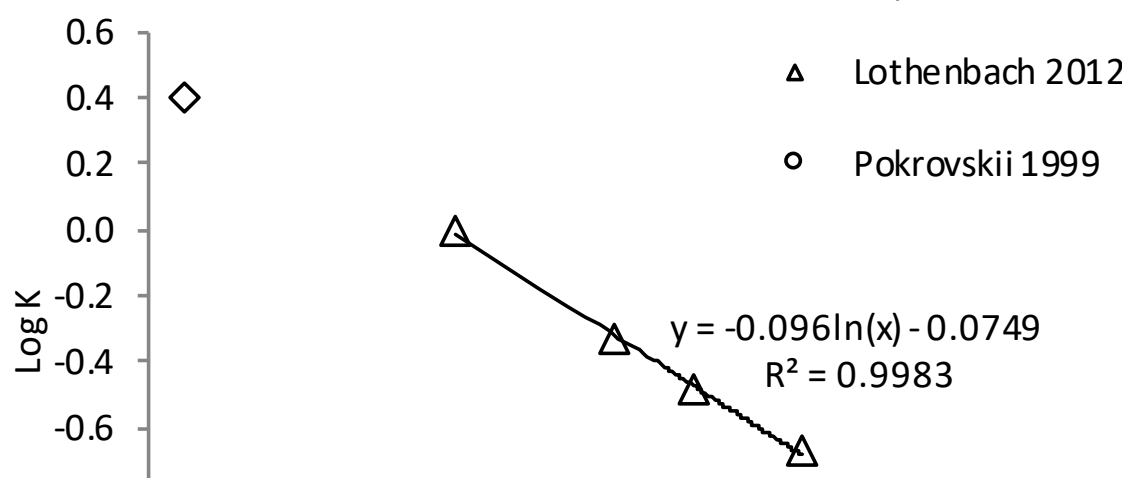

$-0.8$

$-1.0$

$-1.2$

0.001

0.1

$$
\text { Time (days) }
$$

Fig. 16. Solubility of $\mathrm{AH}_{3}$ as a function of time. The solubility change over time was fitted using the data from Lothenbach et al [119]. The data from Capmas and Ménétrier-Sorrentino (3 to 9 minutes) [208] and Pokrovskii and Helgeson [209] (Gibbsite) were omitted from the equation fit because their exact times could not be determined but are shown for reference. Taken from [100]. Copyright needed

\section{Concluding remarks and further perspectives}

In the recent years, a lot of progress has been made on understanding ye'elimite-based cements. Latest advances in clinkering focused mainly on the effect of iron content in the raw meal on ye' elimite formation and its stability. It was found that iron accelerates the ye'elimite formation. Additionally, ye'elimite containing iron seems to possess a lower thermal stability compared to the stoichiometric one and starts to decompose if the sintering temperature is too high and / or dwell time is too long. The decomposition of ye'elimite leads to the volatilization of sulphur and the formation of secondary phases such as mayenite, krotite and ferrite. The XRD detectable quantities of mayenite are typically below $1 \%$ in the solid solution ye'elimite clinker. It is furthermore possible that a part of mayenite is present in an amorphous form.

Concerning hydration kinetics, recent research activities could highlight that the polymorphism alone cannot explain the different hydration kinetics of stoichiometric ye'elimite and the iron-bearing solid solutions and what is observed in CSA and BYF cements. In the literature results or from industrial clinker analysis, the increase of iron content is coupled with a faster rate of hydration of ye'elimite. The presence of secondary mayenite, from the partial decomposition of ye'elimite, can partially explain all observed features. 
Thermodynamic modelling has as well progressed during the last decades. It is possible to predict the pore solution composition at the equilibrium with the hydrates phases present at given hydration time. Several studies demonstrated as well the role of pore solution composition either on the kinetics of reaction in ye'elimite based cements or on the resulting hydrate assemblage.

The slow reaction of silicate phase is related to the pore solution composition and the space filling by the reaction of the more reactive ye'elimite. The ion concentrations in solution are strongly controlled by the Al concentration and $\mathrm{AH}_{3}$. A high concentration limits the dissolution of silicate phases. The thermodynamic modelling does not capture this phenomenon. Though, the modelling indicates that the calcium silicates are more undersaturated in the samples when Al concentration is high.

Despite the high efforts in research on ye'elimite cements and the recent achievements as highlighted in this papers, still open questions need to be solved:

Information on formation rate and stability of ye' elimite in correlation to iron content are missing. Besides iron, several other minor elements such as alkali, boron, chromium, manganese, titanium, phosphate, fluorine and many others are reported for CSA and BYF as well. It is possible that some of these elements affect the formation, composition, stability and hydraulic reactivity of ye'elimite in the same way as iron. Additional systematic studies are needed to better understand their impact on ye'elimite synthesis and the resulting secondary phases.

More complex reactions and interactions could be thus investigated and potentially more industrial byproducts and waste could be used for the production of CSA and BYF clinkers.

Several minor phases such as free lime, periclase, alkali sulphates and Ca-langbeinite are present in ye'elimite-based cements, depending on the choice of raw materials and the process conditions. These minor phases can affect the hydration kinetics. Thermodynamic investigations show for some of them (e.g. alkali sulphate, free lime) some interesting similarities to the mayenite system, especially the acceleration when added together with gypsum. It would be of high scientific as well as industrial relevance to study and verify the mechanisms behind these "similarities" which would enable the better understanding of industrial clinker early hydration.

The evolution of the solution composition is the main factor determining the onset and duration of the hydration stages. The understanding of the effect of the solution composition on the dissolution precipitation reactions is therefore of high importance to minimize the formation of metastable phases 
for a better mechanical performance of the cements. The effect of sulphate source or retarders or their combination on the nucleation and the crystallinity of aluminium should be checked.

The use of retarders such borax, citrate, gluconate or tartrate was already reported for CSA and BYF cements. However, the exact retarding mechanisms, efficiency and effect on the formation of the metastable hydrates of some retarders remain poorly understood. It would be as well important to understand how the different ion such as aluminium, calcium, sulphate interact in solution with these retarders (formation of ion complexes, etc.).

Another necessary problem that needs to be investigated concerns the effect of the temperature on the dissolution and precipitation reactions especially on the crystallinity of previously formed amorphous phases such as aluminium hydroxide, which causes the release of combined water. Further insight in the composition and stability of the formed hydrates could be generated and the dynamics of formation could be verified against the thermodynamics. Based on this, the relationship between the time-temperature history, the crystallinity, hydration state, transformation rates, densities and bound water contents of hydrates and the subsequent space filling potential could be further investigated, including the microstructural evolution.

The effect of iron and its low mobility in the pore solution of hydrating ye'elimite, CSA and BYF on the nucleation, growth, composition and crystallinity of hydrates should be further studied. The question regarding the morphology and the composition of $\mathrm{C}-\mathrm{S}-\mathrm{H}$ in those systems needs further investigation as well.

It is desirable to transfer the collected results and knowledge to industrial scale. This can be done by working with synthetic, model CSA and BYF cements obtained by e.g. blending ye'elimite with other phases such as belite, mayenite, ferrite and different calcium sulphates such as anhydrite and gypsum.

For the performance characterization of these cements, cement producers should be more open to share their data on concretes. Durability tests should range from accelerated laboratory testing to outdoor storage of samples in real environment. This should be undertaken in close collaboration with research institutions to ensure that the performance of ye'elimite cement concretes is generally comparable to common concretes. Recent studies showed that BYF concretes are characterized by different strength development kinetics - a rapid strength gain within the first day or two is followed by a plateau [210]. Depending on the binder composition and storage conditions, the strength can further increase between 2-3 months and 1 year. Another unique property of ye'elimite cement based concretes is their volume 
shrinkage that is 2 to 3 times lower compared to common concrete. Efficiency of common admixtures, airentrainers agent in ettringite systems should be as well studied as the latest were originally developed for Portland clinker-based concretes.

For the application of these cements, new standards and further field application are required to show their versatility. In China, the Third Cement Series is standardized since many years in GB 20472-2006. Different European cement companies obtained European technical approvals for some CSA application and standardization activities may follow. $\mathrm{ACl}$ has recently formed a committee on alternative cements (ACI 242), which covers also CSA. They also released the ITG-10R: Practitioner's Guide for Alternative Cements.

\section{References}

[1] E. Gartner, H. Hirao, A review of alternative approaches to the reduction of $\mathrm{CO} 2$ emissions associated with the manufacture of the binder phase in concrete, Cem. Concr. Res. 78 (2015) 126-142. doi:10.1016/j.cemconres.2015.04.012.

[2] E. Gartner, Industrially interesting approaches to low-CO2 cements, Cem. Concr. Res. 34 (2004) 1489-1498. doi:10.1016/j.cemconres.2004.01.021.

[3] E. Gartner, T. Sui, Alternative cement clinkers, Cem. Concr. Res. (2017). doi:10.1016/J.CEMCONRES.2017.02.002.

[4] W. Dienemann, D. Schmitt, F. Bullerjahn, M. Ben Haha, Belite-Calciumsulfoaluminate-Ternesite (BCT) - A new low-carbon clinker Technology, Cem. Int. 11 (2013). doi:10.1127/14389134/2014/018.

[5] M.C.G. Juenger, F. Winnefeld, J.L. Provis, J.H. Ideker, Advances in alternative cementitious binders, Cem. Concr. Res. (2011). doi:10.1016/j.cemconres.2010.11.012.

[6] A. Klein, G.E. Troxell, Studies of Calcium Sulfoaluminate Admixtures for Expansive Cements, Proc. Am. Soc. Test. Mater. (1958) 986-1008.

[7] L. Zhang, M. Su, Y. Wang, Development of the use of sulfo- and ferroaluminate cements in China, Adv. Cem. Res. (1999). doi:10.1680/adcr.1999.11.1.15.

[8] W.-H. Chae, D.-C. Park, S.-H. Choi, Early Hydration of Modified Belite Cement Prepared by Adding Borax., Korean J. Ceram. 2 (1996) 147-151.

[9] A. Cuesta, E.R. Losilla, M.A.G. Aranda, J. Sanz, Á.G. De La Torre, Reactive belite stabilization mechanisms by boron-bearing dopants, Cem. Concr. Res. (2012). doi:10.1016/j.cemconres.2012.01.006.

[10] R. El Hayek, F. Ferey, P. Florian, A. Pisch, D.R. Neuville, Structure and properties of lime aluminoborate glasses, Chem. Geol. (2017). doi:10.1016/j.chemgeo.2016.11.025.

[11] C. HIRAYAMA, Properties of Aluminoborate Glasses of Group II Metal Oxides: I, Glass Formation 
and Thermal Expansion, J. Am. Ceram. Soc. 44 (1961) 602-606. doi:10.1111/j.11512916.1961.tb11666.x.

[12] M. Garcia-Mate, I. Santacruz, A. Cuesta, L. Leon-Reina, M.A.G. Aranda, I. Baco, V. Morin, G. Walenta, E. Gartner, A.G. De la Torre, Amorphous determination in calcium sulfoaluminate materials by external and internal methods, Adv. Cem. Res. 27 (2015) 417-423. doi:10.1680/adcr.14.00026.

[13] A. Cuesta, A.G. De la Torre, E.R. Losilla, V.K. Peterson, P. Rejmak, A. Ayuela, C. Frontera, M.A.G.G. Aranda, Structure, Atomistic Simulations, and Phase Transition of Stoichiometric Yeelimite, Chem. Mater. 25 (2013) 1680-1687. doi:10.1021/cm400129z.

[14] A. Cuesta, Á.G. De La Torre, E.R. Losilla, I. Santacruz, M.A.G.G. Aranda, Pseudocubic Crystal Structure and Phase Transition in Doped Ye'elimite, Cryst. Growth Des. 14 (2014) 5158-5163. doi:10.1021/cg501290q.

[15] F. Bullerjahn, D. Schmitt, M. Ben Haha, Effect of raw mix design and of clinkering process on the formation and mineralogical composition of (ternesite) belite calcium sulphoaluminate ferrite clinker, Cem. Concr. Res. 59 (2014). doi:10.1016/j.cemconres.2014.02.004.

[16] G.J. Redhammer, G. Tippelt, G. Roth, G. Amthauer, Structural variations in the brownmillerite series $\mathrm{Ca} 2\left(\mathrm{Fe} 2-\mathrm{xAlx}\right.$ )O5: Single-crystal $\mathrm{X}$-ray diffraction at $25^{\circ} \mathrm{C}$ and high-temperature $\mathrm{X}$-ray powder diffraction $\left(25^{\circ} \mathrm{C} \leq \mathrm{T} \leq 1000^{\circ} \mathrm{C}\right.$ ), Am. Mineral. (2004). doi:10.2138/am-2004-2-322.

[17] P. Arjunan, M.R. Silsbee, D.M. Roy, Sulfoaluminate-belite cement from low-calcium fly ash and sulfur-rich and other industrial by-products, Cem. Concr. Res. (1999). doi:10.1016/S00088846(99)00072-1.

[18] E.B. da Costa, E.D. Rodríguez, S.A. Bernal, J.L. Provis, L.A. Gobbo, A.P. Kirchheim, Production and hydration of calcium sulfoaluminate-belite cements derived from aluminium anodising sludge, Constr. Build. Mater. (2016). doi:10.1016/j.conbuildmat.2016.06.022.

[19] Y. Shen, J. Qian, Y. Huang, D. Yang, Synthesis of belite sulfoaluminate-ternesite cements with phosphogypsum, Cem. Concr. Compos. 63 (2015) 67-75. doi:10.1016/j.cemconcomp.2015.09.003.

[20] A. Rungchet, C.S. Poon, P. Chindaprasirt, K. Pimraksa, Synthesis of low-temperature calcium sulfoaluminate-belite cements from industrial wastes and their hydration: Comparative studies between lignite fly ash and bottom ash, Cem. Concr. Compos. (2017). doi:10.1016/j.cemconcomp.2017.06.013.

[21] B.J. DUVALLET, T.; RATHBONE, R. F.; HENKE, K. R.; ROBERT, Low-Energy, Low CO2 - Emitting Cements Produced from Coal Combustion By-Products and Red Mud, in: World Coal Ash Conf., 2009.

[22] I.A. Chen, M.C.G. Juenger, Incorporation of coal combustion residuals into calcium sulfoaluminate-belite cement clinkers, Cem. Concr. Compos. (2012). doi:10.1016/j.cemconcomp.2012.04.006.

[23] A. Telesca, M. Marroccoli, F. Winnefeld, Synthesis and characterization of calcium sulfoaluminate cements produced by different chemical gypsums, Adv. Cem. Res. (2019) in press. 
doi:10.1680/jadcr.18.00122.

1000

1001

1002

1003

1004

1005

1006

1007

1008

1009

1010

1011

1012

1013

1014

1015

1016

1017

1018

1019

1020

1021

1022

1023

1024

1025

1026

1027

1028

1029

1030

1031

1032

1033

1034

1035

[24] E.A. El-Alfi, R.A. Gado, Preparation of calcium sulfoaluminate-belite cement from marble sludge waste, Constr. Build. Mater. (2016). doi:10.1016/j.conbuildmat.2016.03.103.

[25] A. Telesca, M. Marroccoli, M. Tomasulo, G.L. Valenti, H. Dieter, F. Montagnaro, Calcium looping spent sorbent as a limestone replacement in the manufacture of portland and calcium sulfoaluminate cements, Environ. Sci. Technol. (2015). doi:10.1021/acs.est.5b00394.

[26] Á.G. De La Torre, A.J.M. Cuberos, G. Álvarez-Pinazo, A. Cuesta, M.A.G. Aranda, In situ powder diffraction study of belite sulfoaluminate clinkering, J. Synchrotron Radiat. (2011). doi:10.1107/S0909049511005796.

[27] T. Hanein, A. Elhoweris, I. Galan, F.P. Glasser, Campbell, M.N. Bannerman, Thermodynamic data of ye'elemite (C4A3S ) for cement clinker equilibrium calculations., in: 35th Cem. Concr. Sci. Conf., 2015.

[28] T. Hanein, I. Galan, A. Elhoweris, S. Khare, S. Skalamprinos, G. Jen, M. Whittaker, M.S. Imbabi, F.P. Glasser, M.N. Bannerman, Production of belite calcium sulfoaluminate cement using sulfur as a fuel and as a source of clinker sulfur trioxide: pilot kiln trial, Adv. Cem. Res. (2016). doi:10.1680/jadcr.16.00018.

[29] P. Xue, A. Xu, D. He, Q. Yang, G. Liu, F. Engström, B. Björkman, Research on the sintering process and characteristics of belite sulphoaluminate cement produced by BOF slag, Constr. Build. Mater. (2016). doi:10.1016/j.conbuildmat.2016.06.098.

[30] S. Muzhen, D. Junan, W. Zongdao, L. Xiaoxin, Research on the Chemical Composition and Microstructures of Sulpho-Aluminate Cement Clinker, in: 9th Int. Congr. Chem. Cem., New Delhi, 1992: pp. 94-100.

[31] C.W. Bale, P. Chartrand, S.A. Degterov, G. Eriksson, K. Hack, R. Ben Mahfoud, J. Melançon, A.D. Pelton, S. Petersen, FactSage thermochemical software and databases, Calphad Comput. Coupling Phase Diagrams Thermochem. (2002). doi:10.1016/S0364-5916(02)00035-4.

[32] A. Pisch, A. Pasturel, On the heat of formation of ye'elimite Ca4Al6012×SO4 using density functional theory, Adv. Cem. Res. 0 (n.d.) 1-7. doi:10.1680/jadcr.18.00128.

[33] L. Barcelo, J. Kline, G. Walenta, E. Gartner, Cement and carbon emissions, Mater. Struct. Constr. 47 (2014) 1055-1065. doi:10.1617/s11527-013-0114-5.

[34] Y.-P. Jacob, M. Pasquier, D. Renie, G. Beauvent, Optimised vertical-shaft kiln of producing sulfoaluminous clinker, US9422192B2, 2012.

[35] F. Bullerjahn, Characterisation and hydration of ye'elimite containing cements, EPFL, 2018. http://infoscience.epfl.ch/record/254873/files/EPFL_TH7953.pdf.

[36] D. Londono-Zuluaga, J.I. Tobón, M.A.G. Aranda, I. Santacruz, A.G. De la Torre, Clinkering and hydration of belite-alite-ye'elimite cement, Cem. Concr. Compos. (2017). doi:10.1016/j.cemconcomp.2017.04.002.

[37] F. Puertas, M.T.B. Varela, S.G. Molina, Kinetics of the thermal decomposition of C4A3S̄ in air, 
Cem. Concr. Res. (1995). doi:10.1016/0008-8846(95)00046-F.

[38] B. Touzo, K.L. Scrivener, F.P. Glasser, Phase compositions and equilibria in the CaO-Al2O3$\mathrm{Fe} 2 \mathrm{O} 3-\mathrm{SO} 3$ system, for assemblages containing ye'elimite and ferrite $\mathrm{Ca} 2(\mathrm{Al}, \mathrm{Fe}) \mathrm{O} 5$, Cem. Concr. Res. 54 (2013) 77-86. doi:10.1016/J.CEMCONRES.2013.08.005.

[39] P.K. Mehta, Investigations on energy saving cements, World Cem. Techology. (1980).

[40] Y. Pliego-Cuervo, F.P. Glasser, Phase relations and crystal chemistry of apatite and silicocarnotite solid solutions, Cem. Concr. Res. (1978). doi:10.1016/0008-8846(78)90033-9.

[41] T. Hanein, I. Galan, F.P. Glasser, S. Skalamprinos, A. Elhoweris, M.S. Imbabi, M.N. Bannerman, Stability of ternesite and the production at scale of ternesite-based clinkers, Cem. Concr. Res. 98 (2017) 91-100. doi:10.1016/J.CEMCONRES.2017.04.010.

[42] L. Zhang, Microstructure and performance of calcium sulfoaluminate cements, PhD thesis, University of Aberdeen, UK, 2000.

[43] P. Juilland, E. Gallucci, Morpho-topological investigation of the mechanisms and kinetic regimes of alite dissolution, Cem. Concr. Res. 76 (2015) 180-191. doi:10.1016/J.CEMCONRES.2015.06.001.

[44] J.W. Bullard, H.M. Jennings, R.A. Livingston, A. Nonat, G.W. Scherer, J.S. Schweitzer, K.L. Scrivener, J.J. Thomas, Mechanisms of cement hydration, Cem. Concr. Res. 41 (2011) 1208-1223. doi:10.1016/j.cemconres.2010.09.011.

[45] B. Lothenbach, T. Matschei, G. Möschner, F.P. Glasser, Thermodynamic modelling of the effect of temperature on the hydration and porosity of Portland cement, Cem. Concr. Res. 38 (2008) 1-18. doi:10.1016/j.cemconres.2007.08.017.

[46] M. Ben Haha, B. Lothenbach, G. Le Saout, F. Winnefeld, Influence of slag chemistry on the hydration of alkali-activated blast-furnace slag - Part II: Effect of $A \mid<$ inf $>2</$ inf $>0<$ inf $>3</$ inf $>$, Cem. Concr. Res. 42 (2012) 74-83. doi:10.1016/j.cemconres.2011.08.005.

[47] F. Bullerjahn, E. Boehm-Courjault, M. Zajac, M. Ben Haha, K. Scrivener, Hydration reactions and stages of clinker composed mainly of stoichiometric ye'elimite, Cem. Concr. Res. (2019). doi:10.1016/j.cemconres.2018.10.023.

[48] M. Zajac, J. Skocek, F. Bullerjahn, M. Ben Haha, Effect of retarders on the early hydration of calcium-sulpho-aluminate (CSA) type cements, Cem. Concr. Res. 84 (2016). doi:10.1016/j.cemconres.2016.02.014.

[49] F. Winnefeld, B. Lothenbach, Hydration of calcium sulfoaluminate cements - Experimental findings and thermodynamic modelling, Cem. Concr. Res. 40 (2010) 1239-1247. https://www.sciencedirect.com/science/article/pii/S0008884609002294 (accessed January 17, 2019).

[50] A. Cuesta, G. Álvarez-Pinazo, S.G.G. Sanfélix, I. Peral, M.A.G.M.A.G. Aranda, A.G. De la Torre, Hydration mechanisms of two polymorphs of synthetic ye'elimite, Cem. Concr. Res. 63 (2014) 127-136. doi:10.1016/J.CEMCONRES.2014.05.010. 
1073

1074

1075

1076

1077

1078

1079

1080

1081

1082

1083

1084

1085

1086

1087

1088

1089

1090

1091

1092

1093

1094

1095

1096

1097

1098

1099

1100

1101

1102

1103

1104

1105

1106

1107

1108

1109

[51] D. Jansen, A. Spies, J. Neubauer, D. Ectors, F. Goetz-Neunhoeffer, Studies on the early hydration of two modifications of ye'elimite with gypsum, Cem. Concr. Res. 91 (2017) 106-116. doi:10.1016/J.CEMCONRES.2016.11.009.

[52] F. Bullerjahn, M. Zajac, M. Ben Haha, K.L. Scrivener, M. Ben Haha, K.L. Scrivener, M. Ben Haha, K.L. Scrivener, Factors influencing the hydration kinetics of ye'elimite; effect of mayenite, Cem. Concr. Res. (2019). doi:10.1016/j.cemconres.2018.10.026.

[53] S.L. Brantley, A.A. Olsen, Reaction Kinetics of Primary Rock-Forming Minerals under Ambient Conditions, in: Treatise Geochemistry Second Ed., 2013. doi:10.1016/B978-0-08-095975-7.005039.

[54] G.E. Brown, T.P. Trainor, A.M. Chaka, Geochemistry of mineral surfaces and factors affecting their chemical reactivity, in: Chem. Bond. Surfaces Interfaces, 2008. doi:10.1016/B978044452837-7.50008-3.

[55] L. Nicoleau, E. Schreiner, A. Nonat, lon-specific effects influencing the dissolution of tricalcium silicate, Cem. Concr. Res. 59 (2014) 118-138. doi:10.1016/j.cemconres.2014.02.006.

[56] D. Jansen, Dissolution of ye'elimite -personal communications, (2018).

[57] M. Zajac, J. Skocek, C. Stabler, F. Bullerjahn, M. Ben Haha, Hydration and performance evolution of belite-ye'elimite-ferrite cement, Adv. Cem. Res. (2019) in press. doi:10.1680/jadcr.18.00110.

[58] S.W.W. Tang, H.G.G. Zhu, Z.J.J. Li, E. Chen, H.Y.Y. Shao, Hydration stage identification and phase transformation of calcium sulfoaluminate cement at early age, Constr. Build. Mater. 75 (2015) 11-18. https://www.sciencedirect.com/science/article/abs/pii/S0950061814012185 (accessed January 30,2019$)$.

[59] D. Damidot, Calculation of critically supersaturated domains with respect to ettringite in the CaOAl2O3-CaSO4-H2O system at $20^{\circ} \mathrm{C}$, in: 12 th Int. Congr. Chem. Cem., Montreal, Canada, 2007.

[60] M. Zajac, J. Skocek, F. Bullerjahn, B. Lothenbach, K. Scrivener, M. Ben Haha, Early hydration of ye'elimite: insights from thermodynamic modelling, Cem. Concr. Res. under revi (2019).

[61] H. Minard, S. Garrault, L. Regnaud, A. Nonat, Mechanisms and parameters controlling the tricalcium aluminate reactivity in the presence of gypsum, Cem. Concr. Res. 37 (2007) 14181426. doi:10.1016/J.CEMCONRES.2007.06.001.

[62] S. Goto, K.S. You, K. loku, H. Fujimori, Amorphous Layers Controlling the Rate of Hydration of Cement Minerals, J. Ceram. Soc. Japan,. Bd. 112 (2004) 1308-1310.

[63] W. Lan, F.P. Glasser, Hydration of calcium sulphoaluminate cements, Adv. Cem. Res. 8 (1996) 127-134.

[64] A.D. Capmas, D. Ménétrier-Sorrentino, D. Damidot, Effect of temperature on setting time of calcium aluminate cements, in: Proc. Int. Symp. Calcium Aluminate Cem., Cambridge, Great Britain, 1990.

[65] J.-B. Champenois, C.C.D. Coumes, A. Poulesquen, P. Le Bescop, D. Damidot, Beneficial use of a cell coupling rheometry, conductimetry, and calorimetry to investigate the early age hydration of 
calcium sulfoaluminate cement, Rheol. Acta. 52 (2013) 177-187.

[66] T. Scholten, Untersuchungen an sulfatischen Klinkerphasen CO2-armer Zemente, PAPIERFLIE, Technische Universität Clausthal, 2017.

[67] F.M. Lea, P.C. Hewlett, Lea's chemistry of cement and concrete, Elsevier, 2004.

[68] F. Bullerjahn, J. Skocek, M. Ben Haha, K. Scrivener, Chemical shrinkage of ye'elimite with and without gypsum addition, Constr. Build. Mater. 200 (2019) 770-780. doi:10.1016/J.CONBUILDMAT.2018.12.170.

[69] L. Nicoleau, A. Nonat, A new view on the kinetics of tricalcium silicate hydration, Cem. Concr. Res. 86 (2016) 1-11. doi:10.1016/J.CEMCONRES.2016.04.009.

[70] P.H. Hsu, Aluminum Hydroxides and Oxyhydroxides, in: Miner. Soil Environ., Soil Science Society of America, Madison, WI, 1989: pp. 331-378. http://dx.doi.org/10.2136/sssabookser1.2ed.c7.

[71] H. De Hek, R.. Stol, P.. De Bruyn, Hydrolysis-precipitation studies of aluminum(III) solutions. 3. The role of the sulfate ion, J. Colloid Interface Sci. 64 (1978) 72-89. doi:10.1016/00219797(78)90336-3.

[72] K.P. Prodromou, Formation of Aluminum Hydroxides as Influenced by Aluminum Salts and Bases, Clays Clay Miner. 43 (1995) 111-115.

[73] F. Winnefeld, S. Barlag, Calorimetric and thermogravimetric study on the influence of calcium sulfate on the hydration of ye'elimite, J. Therm. Anal. Calorim. 101 (2009) 949-957. doi:10.1007/s10973-009-0582-6.

[74] L. Zhang, M. Su, Y. Wang, Development of the use of sulfo-and ferroaluminate cements in China, Adv. Cem. Res. 11 (1999) 15-21. http://www.icevirtuallibrary.com/content/article/10.1680/adcr.1999.11.1.15.

[75] B. Raab, Synthese und Charakterisierung nanoskaliger hydraulisch hochreaktiver Phasen des Portland- und Tonerdezements, Halle, Univ., 2010.

[76] F. Winnefeld, B. Lothenbach, Phase equilibria in the system Ca4Al6O12SO4 - Ca2SiO4 - CaSO4 $\mathrm{H} 2 \mathrm{O}$ referring to the hydration of calcium sulfoaluminate cements, RILEM Tech. Lett. 1 (2016) 10-16.

[77] J.-B. Champenois, A. Mesbah, C. Cau Dit Coumes, G. Renaudin, F. Leroux, C. Mercier, B. Revel, D. Damidot, Crystal structures of Boro-AFm and sBoro-AFt phases, Cem. Concr. Res. 42 (2012) 1362-1370. doi:10.1016/j.cemconres.2012.06.003.

[78] C. Cau Dit Coumes, M. Dhoury, J.B. Champenois, C. Mercier, D. Damidot, Combined effects of lithium and borate ions on the hydration of calcium sulfoaluminate cement, Cem. Concr. Res. (2017). doi:10.1016/j.cemconres.2017.03.006.

[79] H. Poellmann, S. Auer, H.J. Kuzel, R. Wenda, Solid solution of ettringites. Part II: Incorporation of $\mathrm{B}(\mathrm{OH}) 4$ - and CrO42- in 3CaO·Al2O3.3CaSO4-32H2O, Cem. Concr. Res. (1993). doi:10.1016/00088846(93)90107-K.

[80] J.-B. Champenois, M. Dhoury, C. Cau Dit Coumes, C. Mercier, B. Revel, P. Le Bescop, D. Damidot, 
Influence of sodium borate on the early age hydration of calcium sulfoaluminate cement, Cem. Concr. Res. 70 (2015) 83-93. doi:10.1016/j.cemconres.2014.12.010.

[81] P. Feng, C. Miao, J.W. Bullard, Factors Influencing the Stability of AFm and AFt in the Ca-Al-S-OH System at $25^{\circ} \mathrm{C} .$, J. Am. Ceram. Soc. 99 (2016) 1031-1041. doi:10.1111/jace.13971.

[82] L.G. Baquerizo, T. Matschei, K.L. Scrivener, M. Saeidpour, L. Wadsö, Hydration states of AFm cement phases, Cem. Concr. Res. 73 (2015) 143-157. doi:10.1016/j.cemconres.2015.02.011.

[83] L.G. Baquerizo, T. Matschei, K.L. Scrivener, M. Saeidpour, A. Thorell, L. Wadsö, Methods to determine hydration states of minerals and cement hydrates, Cem. Concr. Res. 65 (2014) 85-95. doi:10.1016/j.cemconres.2014.07.009.

[84] L.G. Baquerizo, T. Matschei, K.L. Scrivener, Impact of water activity on the stability of ettringite, Cem. Concr. Res. 79 (2016) 31-44. doi:10.1016/j.cemconres.2015.07.008.

[85] B. Lothenbach, F. Winnefeld, C. Alder, E. Wieland, P. Lunk, Effect of temperature on the pore solution, microstructure and hydration products of Portland cement pastes, Cem. Concr. Res. 37 (2007) 483-491. doi:10.1016/j.cemconres.2006.11.016.

[86] P.W. Brown, J. V. Bothe, The stability of ettringite, Adv. Cem. Res. (1993). doi:10.1680/adcr.1993.5.18.47.

[87] R. Barbarulo, H. Peycelon, S. Leclercq, Chemical equilibria between C-S-H and ettringite, at 20 and $85^{\circ} \mathrm{C}$, Cem. Concr. Res. (2007). doi:10.1016/j.cemconres.2007.04.013.

[88] T. Nishikawa, K. Suzuki, S. Ito, K. Sato, T. Takebe, Decomposition of synthesized ettringite by carbonation, Cem. Concr. Res. (1992). doi:10.1016/0008-8846(92)90130-N.

[89] A.M. Cody, H. Lee, R.D. Cody, P.G. Spry, The effects of chemical environment on the nucleation, growth, and stability of ettringite [Ca3Al(OH)6]2(SO4)3.26H2O, Cem. Concr. Res. 34 (2004) 869881. doi:10.1016/j.cemconres.2003.10.023.

[90] W. Prince, M. Espagne, P.C. Aitcin, Ettringite formation: A crucial step in cement superplasticizer compatibility, Cem. Concr. Res. (2003). doi:10.1016/S0008-8846(02)01042-6.

[91] P.K. Mehta, Scanning electron micrographic studies of ettringite formation, Cem. Concr. Res. (1976). doi:10.1016/0008-8846(76)90115-0.

[92] T. Matschei, B. Lothenbach, F.P. Glasser, Thermodynamic properties of Portland cement hydrates in the system CaO-Al2O3-SiO2-CaSO4-CaCO3-H2O, Cem. Concr. Res. 37 (2007) 1379-1410. doi:10.1016/j.cemconres.2007.06.002.

[93] D. Damidot, B. Lothenbach, D. Herfort, F.P. Glasser, Thermodynamics and cement science, Cem. Concr. Res. 41 (2011) 679-695. doi:10.1016/j.cemconres.2011.03.018.

[94] B. Lothenbach, D.A. Kulik, T. Matschei, M. Balonis, L. Baquerizo, B. Dilnesa, G.D. Miron, R.J. Myers, Cemdata 18: A chemical thermodynamic database for hydrated Portland cements and alkali-activated materials, Cem. Concr. Res. 115 (2019) 472-506. doi:10.1016/j.cemconres.2018.04.018.

[95] R. Wang, P.M. Wang, Formation of hydrates of calcium aluminates in cement pastes with 
different dosages of SBR powder, Constr. Build. Mater. (2011). doi:10.1016/j.conbuildmat.2010.07.013.

[96] S. Berger, G. Aouad, C. Cau Dit Coumes, P. Le Bescop, D. Damidot, Leaching of calcium sulfoaluminate cement pastes by water at regulated $\mathrm{pH}$ and temperature: Experimental investigation and modeling, Cem. Concr. Res. 53 (2013) 211-220. doi:10.1016/j.cemconres.2013.06.014.

[97] Y. Zhang, J. Chang, J. Zhao, Y. Fang, Nanostructural characterization of $\mathrm{Al}(\mathrm{OH}) 3$ formed during the hydration of calcium sulfoaluminate cement, J. Am. Ceram. Soc. (2018). doi:10.1111/jace.15536.

[98] Y. Zhang, N. Li, W. Yan, Effect of sulfur on the ion concentration of pore solution and the hydration of calcium aluminate cement, Cem. Concr. Compos. (2015). doi:10.1016/j.cemconcomp.2015.05.004.

[99] M. Andac, F.P. Glasser, Pore solution composition of calcium sulfoaluminate cement, Adv. Cem. Res. 11 (1999) 23-26.

[100] C.W. Hargis, B. Lothenbach, C.J. Müller, F. Winnefeld, Further insights into calcium sulfoaluminate cement expansion, Adv. Cem. Res. (2019) in press. doi:10.1680/jadcr.18.00124.

[101] A. Quennoz, K.L. Scrivener, Hydration of C3A-gypsum systems, Cem. Concr. Res. (2012). doi:10.1016/j.cemconres.2012.04.005.

[102] J. Bizzozero, K.L. Scrivener, Limestone reaction in calcium aluminate cement-calcium sulfate systems, Cem. Concr. Res. (2015). doi:10.1016/j.cemconres.2015.05.019.

[103] C. Gosselin, E. Gallucci, K. Scrivener, Influence of self heating and Li2SO4addition on the microstructural development of calcium aluminate cement, Cem. Concr. Res. (2010). doi:10.1016/j.cemconres.2010.06.012.

[104] K. Scrivener, A. Capmas, Calcium aluminate cements, Adv. Concr. Technol. Const. Mater. 2 (2003) 1-2. doi:10.1016/B978-075065686-3/50278-0.

[105] M.J. Sánchez-Herrero, A. Fernández-Jiménez, A. Palomo, Alkaline hydration of tricalcium aluminate, J. Am. Ceram. Soc. (2012). doi:10.1111/j.1551-2916.2012.05348.x.

[106] V. Antonovič, J. Keriene, R. Boris, M. Aleknevičius, The effect of temperature on the formation of the hydrated calcium aluminate cement structure, in: Procedia Eng., 2013. doi:10.1016/j.proeng.2013.04.015.

[107] F. Song, Z. Yu, F. Yang, Y. Lu, Y. Liu, Microstructure of amorphous aluminum hydroxide in belitecalcium sulfoaluminate cement, Cem. Concr. Res. 71 (2015) 1-6. doi:10.1016/J.CEMCONRES.2015.01.013.

[108] J. Chang, Y.Y. Zhang, X.P. Shang, J.Y. Zhao, X. Yu, Effects of amorphous AH3 phase on mechanical properties and hydration process of C4A3S-CSH2-CH-H2O system, Constr. Build. Mater. 133 (2017) 314-322. doi:10.1016/j.conbuildmat.2016.11.111.

[109] A. Cuesta, A.G. De la Torre, I. Santacruz, P. Trtik, J.C. Da Silva, A. Diaz, M. Holler, M.A.G. Aranda, Chemistry and Mass Density of Aluminum Hydroxide Gel in Eco-Cements by Ptychographic X-ray 
[110] Y. Zhang, J. Chang, Microstructural evolution of aluminum hydroxide gel during the hydration of calcium sulfoaluminate under different alkali concentrations, Constr. Build. Mater. 180 (2018) 655-664. doi:10.1016/j.conbuildmat.2018.06.010.

[111] Y.Y. Zhang, J. Chang, J. Ji, AH3 phase in the hydration product system of AFt-AFm-AH3 in calcium sulfoaluminate cements: A microstructural study, Constr. Build. Mater. 167 (2018) 587-596. doi:10.1016/j.conbuildmat.2018.02.052.

[112] A. Cuesta, J.D. Zea-Garcia, A.G.D. la Torre, I. Santacruz, M.A.G. Aranda, Synchrotron pair distribution function analyses of ye'elimite-based pastes, Adv. Cem. Res. (2019) in press. doi:10.1680/jadcr.18.00097.

[113] C.W. Hargis, A.P. Kirchheim, P.J.M.M. Monteiro, E.M. Gartner, Early age hydration of calcium sulfoaluminate (synthetic ye'elimite, $\mathrm{C}(4) \mathrm{A}(3)(\mathrm{S})$ over-bar) in the presence of gypsum and varying amounts of calcium hydroxide, Cem. Concr. Res. 48 (2013) 105-115. doi:10.1016/j.cemconres.2013.03.001.

[114] J. Chang, X. Yu, X.P. Shang, J.Y. Zhao, Y.Y. Zhang, A reaction range for hydration of calcium sulfoaluminate with calcium sulfate and calcium hydroxide: theory and experimental validation, Adv. Cem. Res. 28 (2016) 664-674. doi:10.1680/jadcr.16.00045.

[115] F. Winnefeld, S. Barlag, Influence of calcium sulfate and calcium hydroxide on the hydration of calcium sulfoaluminate clinker, ZKG Int. 62 (2009) 42-53.

[116] C.L. Hu, D.S. Hou, Z.J. Li, Micro-mechanical properties of calcium sulfoaluminate cement and the correlation with microstructures, Cem. Concr. Compos. 80 (2017) 10-16. doi:10.1016/j.cemconcomp.2017.02.005.

[117] X. Carrier, E. Marceau, J.F. Lambert, M. Che, Transformations of $\gamma$-alumina in aqueous suspensions. 1. Alumina chemical weathering studied as a function of $\mathrm{pH}, \mathrm{J}$. Colloid Interface Sci. (2007). doi:10.1016/j.jcis.2006.12.074.

[118] A. Violante, P.M. Huang, Formation Mechanism of Aluminum Hydroxide Polymorphs, Clays Clay Miner. 41 (n.d.) 590-597. doi: 10.1346/CCMN.1993.0410509.

[119] B. Lothenbach, L. Pelletier-Chaignat, F. Winnefeld, Stability in the system CaO-Al2O3-H2O, Cem. Concr. Res. 42 (2012) 1621-1634. doi:10.1016/j.cemconres.2012.09.002.

[120] H. van Straten, P. de Bruyn, Precipitation from Supersaturated Aluminate Solutions, J. Colloid Interface Sci. (1984).

[121] X. hong GUAN, G. hao CHEN, C. SHANG, ATR-FTIR and XPS study on the structure of complexes formed upon the adsorption of simple organic acids on aluminum hydroxide, J. Environ. Sci. (2007). doi:10.1016/S1001-0742(07)60073-4.

[122] X. Du, Y. Wang, X. Su, J. Li, Influences of pH value on the microstructure and phase transformation of aluminum hydroxide, Powder Technol. (2009). doi:10.1016/j.powtec.2008.11.008. 
[123] D. Gastaldi, G. Paul, L. Marchese, S. Irico, E. Boccaleri, S. Mutke, L. Buzzi, F. Canonico, Hydration products in sulfoaluminate cements: Evaluation of amorphous phases by XRD/solid-state NMR, Cem. Concr. Res. 90 (2016) 162-173. doi:10.1016/J.CEMCONRES.2016.05.014.

[124] L. Pelletier-Chaignat, F. Winnefeld, B. Lothenbach, G. Le Saout, C.J. Müller, C. Famy, Influence of the calcium sulphate source on the hydration mechanism of Portland cement-calcium sulphoaluminate clinker-calcium sulphate binders, Cem. Concr. Compos. 33 (2011) 551-561. doi:10.1016/j.cemconcomp.2011.03.005.

[125] J.J. Wolf, D. Jansen, F. Goetz-Neunhoeffer, J. Neubauer, Mechanisms of early ettringite formation in ternary CSA-OPC-anhydrite systems, Adv. Cem. Res. (2018) 1-11. doi:10.1680/jadcr.18.00115.

[126] A.B. Kudryavtsev, T. V. Kouznetsova, A. V. Pyatkova, Proton relaxation and high resolution solid state Al 27 NMR study of hydration of calcium oxide sulfoaluminate, Cem. Concr. Res. (1990). doi:10.1016/0008-8846(90)90031-R.

[127] F. Bullerjahn, M. Zajac, M. Ben Haha, CSA raw mix design: effect on clinker formation and reactivity, Mater. Struct. (2014). doi:10.1617/s11527-014-0451-z.

[128] L. Pelletier, F. Winnefeld, B. Lothenbach, The ternary system Portland cement-calcium sulphoaluminate clinker-anhydrite: Hydration mechanism and mortar properties, Cem. Concr. Compos. 32 (2010) 497-507. doi:10.1016/j.cemconcomp.2010.03.010.

[129] G. Le Saoût, B. Lothenbach, A. Hori, T. Higuchi, F. Winnefeld, Hydration of Portland cement with additions of calcium sulfoaluminates, Cem. Concr. Res. 43 (2013) 81-94. doi:10.1016/j.cemconres.2012.10.011.

[130] A. Telesca, M. Marroccoli, M.L. Pace, M. Tomasulo, G.L. Valenti, P.J.M. Monteiro, A hydration study of various calcium sulfoaluminate cements, Cem. Concr. Compos. 53 (2014) 224-232. doi:10.1016/j.cemconcomp.2014.07.002.

[131] P. Chaunsali, P. Mondal, Physico-chemical interaction between mineral admixtures and OPCcalcium sulfoaluminate (CSA) cements and its influence on early-age expansion, Cem. Concr. Res. (2016). doi:10.1016/j.cemconres.2015.11.003.

[132] L. Pelletier, F. Winnefeld, B. Lothenbach, The ternary system Portland cement-calcium sulphoaluminate clinker-anhydrite: Hydration mechanism and mortar properties, Cem. Concr. Compos. (2010). doi:10.1016/j.cemconcomp.2010.03.010.

[133] E. Pustovgar, R.K. Mishra, M. Palacios, J.-B. d'Espinose de Lacaillerie, T. Matschei, A.S. Andreev, H. Heinz, R. Verel, R.J. Flatt, Influence of aluminates on the hydration kinetics of tricalcium silicate, Cem. Concr. Res. 100 (2017) 245-262. doi:10.1016/J.CEMCONRES.2017.06.006.

[134] M. Zajac, S. Hoock, C. Stabler, M. Ben Haha, Effect of hydration kinetics on properties of compositionally similar binders, Cem. Concr. Res. 101 (2017). doi:10.1016/j.cemconres.2017.08.005.

[135] J. Nehring, J. Neubauer, S. Berger, F. Goetz-Neunhoeffer, Acceleration of OPC by CAC in binary and ternary systems: The role of pore solution chemistry, Cem. Concr. Res. (2018). doi:10.1016/j.cemconres.2018.02.012. 
[136] E. Pustovgar, R.P. Sangodkar, A.S. Andreev, M. Palacios, B.F. Chmelka, R.J. Flatt, J.-B. d'Espinose de Lacaillerie, Understanding silicate hydration from quantitative analyses of hydrating tricalcium silicates, Nat. Commun. 7 (2016) 10952. doi:10.1038/ncomms10952.

[137] M. Montes, E. Pato, P.M. Carmona-Quiroga, M.T. Blanco-Varela, Can calcium aluminates activate ternesite hydration?, Cem. Concr. Res. 103 (2018) 204-215. doi:10.1016/j.cemconres.2017.10.017.

[138] L.H.J. Martin, F. Winnefeld, E. Tschopp, C.J. Müller, B. Lothenbach, Influence of fly ash on the hydration of calcium sulfoaluminate cement, Cem. Concr. Res. 95 (2017) 152-163. doi:10.1016/j.cemconres.2017.02.030.

[139] C. Gosselin, K.L. Scrivener, Microstructure development of calcium aluminate cements accelerated by lithium sulphate, in: C. Fentiman, R. Mangabhai, K.L. Scrivener (Eds.), Calcium Aluminate Cem. Proc. Centen. Conf. 2008, Palais Des Papes, Avignon, Fr. June 30 - July 2, 2008, IHS BRE Press, Garston, Watford, UK, 2008: pp. 109-122.

[140] F. Winnefeld, L.H.J. Martin, C.J. Müller, B. Lothenbach, Using gypsum to control hydration kinetics of CSA cements, Constr. Build. Mater. (2017). doi:10.1016/j.conbuildmat.2017.07.217.

[141] B. Lothenbach, F. Winnefeld, Thermodynamic modelling of cement hydration: Portland cements - blended cements - calcium sulfoaluminate cements, H. Pöllmann Cem. Mater. Compos. Prop. Appl. Gruyter, Berlin, Boston. , 2017, Pp. 103-143. (n.d.).

[142] V. Morin, P. Termkhajornkit, B. Huet, G. Pham, Impact of quantity of anhydrite, water to binder ratio, fineness on kinetics and phase assemblage of belite-ye' elimite-ferrite cement, Cem. Concr. Res. 99 (2017) 8-17. doi:10.1016/J.CEMCONRES.2017.04.014.

[143] S. Berger, C.C.D. Coumes, P. Le Bescop, D. Damidot, Influence of a thermal cycle at early age on the hydration of calcium sulphoaluminate cements with variable gypsum contents, Cem. Concr. Res. 41 (2011) 149-160. doi:10.1016/j.cemconres.2010.10.001.

[144] J. Kaufmann, F. Winnefeld, B. Lothenbach, Stability of ettringite in CSA cement at elevated temperatures, Adv. Cem. Res. 28 (2016) 251-261. doi:10.1680/jadcr.15.00029.

[145] P.M. Wang, N. Li, L.L. Xu, Hydration evolution and compressive strength of calcium sulphoaluminate cement constantly cured over the temperature range of 0 to $80^{\circ} \mathrm{C}, \mathrm{Cem}$. Concr. Res. 100 (2017) 203-213. doi:10.1016/j.cemconres.2017.05.025.

[146] N. Chitvoranund, F. Winnefeld, C.W. Hargis, S. Sinthupinyo, B. Lothenbach, Synthesis and hydration of alite-calcium sulfoaluminate cement, Adv. Cem. Res. (2017). doi:10.1680/jadcr.16.00071.

[147] F.R. Venema, J.A. Peters, H. van Bekkum, Multinuclear magnetic resonance study of the interaction of aluminium(III)-(+)-tartrate complexes with additional metal ions in aqueous solution, Inorganica Chim. Acta. (1992). doi:10.1016/S0020-1693(00)85511-5.

[148] M. Bishop, A.R. Barron, Cement hydration inhibition with sucrose, tartaric acid, and lignosulfonate: Analytical and spectroscopic study, Ind. Eng. Chem. Res. (2006). doi:10.1021/ie060806t. 
1334

1335

1336

1337

1338

1339

1340

1341

1342

1343

1344

1345

1346

1347

1348

1349

1350

1351

1352

1353

1354

1355

1356

1357

1358

1359

1360

1361

1362

1363

1364

1365

1366

1367

1368

1369

1370

1371

[149] J. Plank, P. Chatziagorastou, C. Hirsch, New model describing distribution of adsorbed superplasticizer on the surface of hydrating cement grain, Jianzhu Cailiao Xuebao/Journal Build. Mater. (2007).

[150] J. Wolska, M. Bryjak, Methods for boron removal from aqueous solutions - A review, Desalination. (2013). doi:10.1016/j.desal.2012.08.003.

[151] L. Fernández-Carrasco, F. Puertas, M.T. Blanco-Varela, T. Vázquez, J. Rius, Synthesis and crystal structure solution of potassium dawsonite: An intermediate compound in the alkaline hydrolysis of calcium aluminate cements, Cem. Concr. Res. (2005). doi:10.1016/j.cemconres.2004.04.018.

[152] J. Cheung, A. Jeknavorian, L. Roberts, D. Silva, Impact of admixtures on the hydration kinetics of Portland cement, Cem. Concr. Res. (2011). doi:10.1016/j.cemconres.2011.03.005.

[153] L. Zhang, L.J.J. Catalan, R.J. Balec, A.C. Larsen, H.H. Esmaeili, S.D. Kinrade, Effects of saccharide set retarders on the hydration of ordinary portland cement and pure tricalcium silicate, J. Am. Ceram. Soc. (2010). doi:10.1111/j.1551-2916.2009.03378.x.

[154] B.J. Smith, A. Rawal, G.P. Funkhouser, L.R. Roberts, V. Gupta, J.N. Israelachvili, B.F. Chmelka, Origins of saccharide-dependent hydration at aluminate, silicate, and aluminosilicate surfaces, Proc. Natl. Acad. Sci. (2011). doi:10.1073/pnas.1104526108.

[155] B.J. Smith, L.R. Roberts, G.P. Funkhouser, V. Gupta, B.F. Chmelka, Reactions and surface interactions of saccharides in cement slurries, Langmuir. (2012). doi:10.1021/la3015157.

[156] S. Sahu, J. Havlica, V. Tomkova, J. Majling, Hydration behavior of sulfoaluminate belite cement in the presence of various calcium sulfates, Thermochim. Acta. 175 (1991) 45-52. doi:10.1016/0040-6031(91)80244-d.

[157] S. Allevi, M. Marchi, F. Scotti, S. Bertini, C. Cosentino, Hydration of calcium sulphoaluminate clinker with additions of different calcium sulphate sources, Mater. Struct. 49 (2016) 453-466.

[158] G. Alvarez-Pinazo, I. Santacruz, M.A.G. Aranda, A.G. De la Torre, Hydration of belite-ye'elimiteferrite cements with different calcium sulfate sources, Adv. Cem. Res. 28 (2016) 529-543. doi:10.1680/jadcr.16.00030.

[159] M. García-Maté, A.G. De la Torre, L. León-Reina, E.R. Losilla, M.A.G. Aranda, I. Santacruz, M. Garcia-Mate, A.G. De la Torre, L. Leon-Reina, E.R. Losilla, M.A.G. Aranda, I. Santacruz, Effect of calcium sulfate source on the hydration of calcium sulfoaluminate eco-cement, Cem. Concr. Compos. 55 (2015) 53-61. doi:10.1016/j.cemconcomp.2014.08.003.

[160] Y. Jeong, C.W. Hargis, S.C. Chun, J. Moon, The effect of water and gypsum content on strätlingite formation in calcium sulfoaluminate-belite cement pastes, Constr. Build. Mater. (2018). doi:10.1016/j.conbuildmat.2018.01.153.

[161] I. Santacruz, Á.G. De la Torre, G. Álvarez-Pinazo, A. Cabeza, A. Cuesta, J. Sanz, M.A.G. Aranda, Structure of stratlingite and effect of hydration methodology on microstructure, Adv. Cem. Res. (2016). doi:10.1680/adcr.14.00104.

[162] H. Minard, Etude intégrée des processus d'hydratation, de coagulation, de rigidification et de prise pour un système C3S-C3A-sulfates-alcalins, PhD-Thesis, Univ. Bourgogne, Dijon, Fr. 2003. 
(n.d.).

[163] A. Garrault, A. Nonat, Y. Sallier, L. Nicoleau, On the origin of the dormant period of cement hydration, 13th Int. Congr. Chem. Cem. Madrid, Spain, July 3-8, 2011. (n.d.).

[164] A. Schöler, B. Lothenbach, F. Winnefeld, M.B. Haha, M. Zajac, H.-M. Ludwig, Early hydration of SCM-blended Portland cements: A pore solution and isothermal calorimetry study, Cem. Concr. Res. 93 (2017). doi:10.1016/j.cemconres.2016.11.013.

[165] G. Bernardo, A. Telesca, G.L. Valenti, A porosimetric study of calcium sulfoaluminate cement pastes cured at early ages, Cem. Concr. Res. 36 (2006) 1042-1047. doi:10.1016/j.cemconres.2006.02.014.

[166] F.P.P. Glasser, L. Zhang, High-performance cement matrices based on calcium sulfoaluminatebelite compositions, Cem. Concr. Res. 31 (2001) 1881-1886. doi:10.1016/S0008-8846(01)006494.

[167] P. Lura, F. Winnefeld, X. Fang, A simple method for determining the total amount of physically and chemically bound water of different cements, J. Therm. Anal. Calorim. (2017). doi:10.1007/s10973-017-6513-z.

[168] L. Zhang, F.P. Glasser, Investigation of the microstructure and carbonation of $\mathrm{CS}^{-} \mathrm{A}$-based concretes removed from service, Cem. Concr. Res. 35 (2005) 2252-2260. doi:10.1016/j.cemconres.2004.08.007.

[169] F.P. Glasser, J. Marchand, E. Samson, Durability of concrete - Degradation phenomena involving detrimental chemical reactions, Cem. Concr. Res. 38 (2008) 226-246. doi:10.1016/j.cemconres.2007.09.015.

[170] F. Winnefeld, M. Ben Haha, B. Lothenbach, Hydration mechanisms of calcium sulfoaluminate cements assessed by scanning electron microscopy and thermodynamic modeling, Int. Congr. Chem. Cem. Madrid, Spain, July 3-8, 2011, 7 Pp. (n.d.).

[171] H. Beltagui, G. Jen, M. Whittaker, M.S. Imbabi, The influence of variable gypsum and water content on the strength and hydration of a belite-calcium sulphoaluminate cement, Adv. Appl. Ceram. 116 (2017) 199-206. doi:10.1080/17436753.2017.1289722.

[172] F. Winnefeld, C.W. Hargis, S. Steiner, J. Kaufmann, A. Borgschulte, M. Marchi, S. Allevi, B. Lothenbach, Carbonation resistance of calcium sulfoaluminate cement mortars, Conf. to Celebr. Centen. LMC Karen Scrivener's 60th Birthday, Lausanne, Switzerland, August 19-22, 2018. (n.d.) 4 pp.

[173] L.J. Struble, P.W. Brown, Heats of dehydration and specific-heats of compounds found in concrete and their potential for thermal-energy storage, Sol. Energy Mater. 14 (1986) 1-12. doi:10.1016/0165-1633(86)90008-0.

[174] Q. Zhou, E.E. Lachowski, F.P. Glasser, Metaettringite, a decomposition product of ettringite, Cem. Concr. Res. 34 (2004) 703-710. doi:10.1016/j.cemconres.2003.10.027.

[175] F. Winnefeld, J. Kaufmann, Concrete produced with calcium sulfoaluminate cement - a potential system for energy and heat storage, First Middle East Conf. Smart Monit. Assess. Rehabil. Civ. 
Struct. Dubai, United Arab Emirates, Febr. 8-10, 2011, Pap. No. 70. (n.d.).

[176] K. Ndiaye, S. Ginestet, M. Cyr, Thermal energy storage based on cementitious materials: A review, Aims Energy. 6 (2018) 97-120. doi:10.3934/energy.2018.1.97.

[177] J. Kaufmann, F. Winnefeld, Zementbasierter chemischer Energiespeicher (Cement-based chemical energy stores), Swiss Pat. Appl. No. 00840/10, May 27, 2010, PCT Appl. No. WO2011147748 A1, December 1, 2011. (n.d.).

[178] K. Ndiaye, S. Ginestet, M. Cyr, Modelling and experimental study of low temperature energy storage reactor using cementitious material, Appl. Therm. Eng. 110 (2017) 601-615. doi:10.1016/j.applthermaleng.2016.08.157.

[179] K. Ndiaye, S. Ginestet, M. Cyr, Experimental evaluation of two low temperature energy storage prototypes based on innovative cementitious material, Appl. Energy. 217 (2018) 47-55. doi:10.1016/j.apenergy.2018.02.136.

[180] B. Lothenbach, D. Damidot, T. Matschei, J. Marchand, Thermodynamic modelling: state of knowledge and challenges, Adv. Cem. Res. 22 (2010) 211-223. doi:10.1680/adcr.2010.22.4.211.

[181] B. Lothenbach, M. Zajac, Application of thermodynamic modelling to hydrated cements, Cem. Concr. Res. (2019) in press.

[182] B. Lothenbach, Thermodynamic equilibrium calculations in cementitious systems, Mater. Struct. 43 (2010) 1413-1433. doi:10.1617/s11527-010-9592-x.

[183] P. Blanc, X. Bourbon, A. Lassin, E.C. Gaucher, Chemical model for cement-based materials: Thermodynamic data assessment for phases other than C-S-H, Cem. Concr. Res. 40 (2010) 13601374. doi:http://dx.doi.org/10.1016/j.cemconres.2010.04.003.

[184] W. Hummel, U. Berner, E. Curti, F.J. Pearson, T. Thoenen, Nagra/PSI chemical thermodynamic data base 01/01, Radiochim. Acta. 90 (2002) 805-813.

[185] J. Wang, Hydration mechanism of cements based on low-CO2 clinkers containing belite, ye'elimite and calcium alumino-ferrite, Université des Sciences et Technologie de Lille-Lille I, 2010. https://tel.archives-ouvertes.fr/tel-00595554/.

[186] I. Kaprálik, F. Hanic, Phase relations in the subsystem C4A3S国SH2] $\mathrm{CH}$ ?H2O of the system CaOlal2O3]CS? 20 referred to hydration of sulphoaluminate cement, Cem. Concr. Res. 19 (1989) 89-102. doi:10.1016/0008-8846(89)90069-0.

[187] H.F. Taylor, Cement Chemistry, n.d.

[188] F. Winnefeld, B. Lothenbach, Thermodynamic modeling of the hydration of calcium sulfoaluminate cements blended with mineral additions, 1st Int. Conf. Sulphoaluminate Cem. Mater. Eng. Technol. Wuhan, China, Oct. 23-24, 2013. (n.d.) 212-228.

[189] L.H.J. Martin, F. Winnefeld, C.J. Müller, B. Lothenbach, Contribution of limestone to the hydration of calcium sulfoaluminate cement, Cem. Concr. Compos. 62 (2015) 204-211. doi:10.1016/j.cemconcomp.2015.07.005.

[190] L. Pelletier-Chaignat, F. Winnefeld, B. Lothenbach, C.J. Müller, Beneficial use of limestone filler 
with calcium sulphoaluminate cement, Constr. Build. Mater. 26 (2012) 619-627. doi:10.1016/j.conbuildmat.2011.06.065.

[191] M.T. Pedersen, B. Lothenbach, F. Winnefeld, J. Skibsted, Hydrate phase assemblages in calcium sulfoaluminate - metakaolin - limestone blends, F. Martirena, A. Favier, K. Scrivener (Eds.), RILEM Bookseries Vol. 16, Proc. 2nd Int. Conf. Calcined Clays Sustain. Concr. December 5-7, 2017. (n.d.) $352-357$.

[192] C. Cau Dit Coumes, O. Farcy, P. Antonucci, J.-B. Champenois, D. Lambertin, A. Mesbah, Design of self-desiccating binders using CSA cement: influence of the cement composition and sulfate source, Adv. Cem. Res. (2019) in press. doi:10.1680/jadcr.18.00100.

[193] P. Chaunsali, P. Mondal, Influence of Calcium Sulfoaluminate (CSA) Cement Content on Expansion and Hydration Behavior of Various Ordinary Portland Cement-CSA Blends, J. Am. Ceram. Soc. (2015). doi:10.1111/jace.13645.

[194] P. Chaunsali, P. Mondal, Hydration and early-age expansion of calcium sulfoaluminate cementbased binders: experiments and thermodynamic modeling, J. Sustain. Cem. Mater. 5 (2016) 259267. doi:10.1080/21650373.2015.1060184.

[195] C.W. Hargis, B. Lothenbach, C.J. Müller, F. Winnefeld, Carbonation of calcium sulfoaluminate mortars, Cem. Concr. Compos. 80 (2017) 123-134. doi:10.1016/J.CEMCONCOMP.2017.03.003.

[196] D. Gastaldi, F. Bertola, F. Canonico, L. Buzzi, S. Mutke, S. Irico, G. Paul, L. Marchese, E. Boccaleri, A chemical/mineralogical investigation of the behavior of sulfoaluminate binders submitted to accelerated carbonation, Cem. Concr. Res. 109 (2018) 30-41. doi:10.1016/j.cemconres.2018.04.006.

[197] D. Damidot, S.J. Barnett, F.P. Glasser, D.E. Macphee, Investigation of the CaO-Al2O3-SiO2-CaSO4CaCO3- $\mathrm{H} 2 \mathrm{O}$ system at $25^{\circ} \mathrm{C}$ by thermodynamic calculation, Adv. Cem. Res. 16 (2004) 69-76. doi:10.1680/adcr.16.2.69.36253.

[198] D. Damidot, F.P. Glasser, Investigation of the CaO-Al2O3-SiO2-H2O system at $25 \mathrm{C}$ by thermodynamic calculations, Cem. Concr. Res. 25 (1995) 22-28.

[199] F. Winnefeld, B. Lothenbach, Phase equilibria in the system Ca 4 Al 6012 SO 4-Ca 2 SiO 4-CaSO 4-H 2 O referring to the hydration of calcium sulfoaluminate cements, RILEM Tech. Lett. 1 (2016) $10-16$.

[200] H. Winkler, Über mechanische Eigenschaften von normalfestem und hochfestem Beton unter besonderer Berücksichtigung des Elastizitätsmoduls, BAM Bundesanstalt für Materialforschung und -prüfung, Berlin, 2010.

[201] B. Lothenbach, G. Le Saout, E. Gallucci, K. Scrivener, Influence of limestone on the hydration of Portland cements, Cem. Concr. Res. 38 (2008) 848-860. doi:10.1016/j.cemconres.2008.01.002.

[202] M. Zajac, A. Rossberg, G. Le Saout, B. Lothenbach, Influence of limestone and anhydrite on the hydration of Portland cements, Cem. Concr. Compos. 46 (2014) 99-108. doi:10.1016/j.cemconcomp.2013.11.007.

[203] W.L. Wang, X.D. Chen, Y. Chen, Y. Dong, C.Y. Ma, Calculation and Verification for the 
Thermodynamic Data of 3CaO×3Al2O3×CaSO4, Chinese J. Chem. Eng. 19 (2011) 489-495. doi:10.1016/s1004-9541(11)60011-6.

[204] J. Havlica, S. Sahu, Thermodynamics and kinetics in the system Ca4(Al6O12)(SO4)-CaSO4 $\times 2 \mathrm{H} 2 \mathrm{O}-$ $\mathrm{H} 2 \mathrm{O}$ up to $75^{\circ} \mathrm{C}$, 9th Int. Congr. Chem. Cem. Noember 23-28, 1992, New Delhi, India. Volume IV (n.d.) 157-163.

[205] S. Skalamprinos, I. Galan, T. Hanein, F. Glasser, Enthalpy of formation of ye'elimite and ternesite, J. Therm. Anal. Calorim. 131 (2018) 2345-2359. doi:10.1007/s10973-017-6751-0.

[206] D. Jansen, F. Goetz-Neunhoeffer, B. Lothenbach, J. Neubauer, The early hydration of Ordinary Portland Cement (OPC): An approach comparing measured heat flow with calculated heat flow from QXRD, Cem. Concr. Res. 42 (2012) 134-138. doi:10.1016/j.cemconres.2011.09.001.

[207] B. Lothenbach, K. Scrivener, R.D. Hooton, Supplementary cementitious materials, Cem. Concr. Res. 41 (2011) 1244-1256. http://www.sciencedirect.com/science/article/pii/\$0008884610002632.

[208] A. Capmas, D. Ménétrier-Sorrentino, The effect of temperature on the hydration of calcium aluminate cement, Proc. Unified Int. Tech. Conf. Refract. First Bienn. Worldw. Conf. Refract. Novemb. 1-4, 1989, Anaheim, CA, USA, Vol. 2. Ed. by L. J. Trostel, Jr. Am. Ceram. Soc. Westerville, $\mathrm{OH}, \mathrm{USA}$, . (n.d.) $1157-1170$.

[209] V.A. Pokrovskii, H.C. Helgeson, Thermodynamic properties of aqueous species and the solubilities of minerals at high pressures and temperatures: The system Al2O3-H2O-NaCl, Am. J. Sci. 295 (1995) 1255-1342. doi:10.2475/ajs.295.10.1255.

[210] K. Quillin, Performance of belite-sulfoaluminate cements, Cem. Concr. Res. 31 (2001) 13411349. doi:10.1016/S0008-8846(01)00543-9. 